\title{
Numerical Distribution Functions for Seasonal Unit Root Tests \\ with OLS and GLS Detrending
}

\author{
Tomás del Barrio Castro ${ }^{1}$, Andrii Bodnar ${ }^{2}$ and Andreu Sansó ${ }^{3}$
}

\begin{abstract}
This paper implements the approach introduced by MacKinnon $(1994,1996)$ to estimate the response surface of the test statistics of seasonal unit root tests with OLS and GLS detrending for quarterly and monthly time series. The Gauss code that is available in the supplementary material of the paper produces $p$-values for five test statistics depending on the sample size, deterministic terms and frequency of the data. A comparison with previous studies is undertaken, and an empirical example using airport passenger arrivals to a tourist destination is carried out. Quantile function coefficients are reported for simple computation of critical values for tests at $1 \%, 5 \%$ and $10 \%$ significance levels.
\end{abstract}

Key words: HEGY test, GLS detrending, response surfaces

\section{1.- Introduction}

It is common practice to test for the presence of seasonal unit roots in data recorded at intervals of less than one year. The paper by Hylleberg, Engle, Granger and Yoo (1990) (henceforth HEGY) suggests a set of filters and corresponding tests that consider unit roots separately at each seasonal and zero frequencies for quarterly data. Beaulieu and Miron (1993) and Taylor (1998) extend the HEGY approach to the monthly case, and extensions for an arbitrary number of seasons $(S)$ per year can be found in Smith and Taylor (1999) and Smith et al. (2009). In order to improve the size and power properties of HEGY tests in the presence of deterministic components, Rodrigues and Taylor (2007) adopt the Generalized Least Squares (GLS) detrending procedure for seasonal unit root tests. The procedure was originally introduced by Elliot, Rothenberg and Stock (1996) for zero frequency unit root tests.

The (seasonal) unit root tests have non-standard distributions, and the most common way to calculate the critical values is with Monte Carlo simulations. Harvey and van Dijk (2006) estimate response surface regressions to compute critical values for conventional HEGY tests in the quarterly case considering only two specifications for the deterministic part (seasonal intercepts and seasonal intercepts with a zero frequency deterministic trend). Diaz-Emparanza (2014) extends the method of Harvey and van Dijk to any seasonal frequency of data following MacKinnon $(1994,1996)$ and obtains $p$-values for the test statistics of the HEGY approach using OLS detrending and considering four specifications of the deterministic part of the seasonal process (zero frequency intercept, zero frequency intercept with trend, seasonal intercepts and seasonal intercepts with zero frequency trend).

In this paper we go further and following the approach suggested by MacKinnon $(1994,1996)$ estimate response surfaces and obtain $p$-values for the test statistics of the HEGY approach considering OLS and GLS detrending for quarterly and monthly data. Finally, for both OLS and GLS detrending we consider five

\footnotetext{
${ }^{1}$ Department of Applied Economics. University of the Balearic Islands. E-mail: tomas.barrio@uib.es.

2 E-mail: andrii.bodnar@gmail.com.

${ }^{3}$ Corresponding author. Department of Applied Economics. University of the Balearic Islands. E-mail: andreu.sanso@uib.es.
} 
specifications of the deterministic part: zero frequency intercept, zero frequency intercept with trend, seasonal intercepts, seasonal intercepts with zero frequency trend and seasonal intercepts with trends.

All of the simulations are done in the GAUSS ${ }^{\mathrm{TM}}$ programming language. The results are compiled into a GAUSS $^{\mathrm{TM}}$ subroutine and are provided in the supplementary material of the paper. Interested persons can use the same subroutine for obtaining $p$-values of HEGY tests.

\section{2.- Seasonal unit root test context}

The general model used in seasonal unit root testing is as follows:

$$
\begin{aligned}
& y_{S t+s}=\mu_{S t+s}+x_{S t+s} \\
& \alpha(L) x_{S t+s}=u_{S t+s}, s=1-S, \ldots, 0, \quad t=1,2, \ldots, T
\end{aligned}
$$

Where it is assumed that the observed time series $y_{S t+s}$ can be decomposed into two parts, the deterministic part $\mu_{S t+s}$ and the stochastic part $x_{S t+s}$. $S$ denotes the number of seasons. In the case of monthly data $S=12$ and in the quarterly case $S=4$; hence, in the rest of the paper we are going to assume that $S$ is even. $T$ represents the number of years.

$\alpha(L)$ is an AR(S) polynomial, $\alpha(L)=\left(1-\alpha_{1} L-\alpha_{2} L^{2}-\cdots--\alpha_{S} L^{S}\right)$ where $L$ is the usual lag operator.

This polynomial can be factorized as:

$$
\alpha(L)=\left(1-\alpha_{0} L\right)\left(1+\alpha_{S / 2} L\right) \prod_{j=1}^{S^{*}}\left(1-2\left[\alpha_{j} \cos \left(\frac{2 \pi j}{S}\right)-\beta_{j} \sin \left(\frac{2 \pi j}{S}\right)\right] L+\left(\alpha_{j}^{2}+\beta_{j}^{2}\right) L^{2}\right)
$$

with $S^{*}=S / 2-1$. Our focus is to test for the presence of unit roots in the polynomial $\alpha(L)$. Note that the parameter $\alpha_{0}$ of $\left(1-\alpha_{0} L\right)$ is associated with the zero frequency, the parameter $\alpha_{S / 2}$ of $\left(1+\alpha_{S / 2} L\right)$ is associated with the Nyquist frequency $(\pi)$ and the parameters $\alpha_{j}$ and $\beta_{j}$ of $\left(1-2\left[\alpha_{j} \cos \left(\frac{2 \pi j}{S}\right)-\beta_{j} \sin \left(\frac{2 \pi j}{S}\right)\right] L+\left(\alpha_{j}^{2}+\beta_{j}^{2}\right) L^{2}\right)$ are associated with the conjugate (harmonic) seasonal frequencies $\frac{2 \pi j}{S}$ and $2 \pi-\frac{2 \pi j}{S}$ for $j=1, \ldots, S^{*}=S / 2-1$.

Regarding the deterministic part $\mu_{S t+s}$, and following Smith and Taylor (1998), Rodriguez and Taylor (2007) and Smith, Taylor and del Barrio Castro (2009), it is possible to define six scenarios: no deterministic terms, zero frequency intercept (one intercept), zero frequency intercept with trend, seasonal intercepts, seasonal intercepts with zero frequency trend and seasonal intercepts with trends. In this paper we do not pay attention to the first case and only consider the following five relevant cases, for $\mu_{S t+s}=\delta^{\prime} z_{S t+s, \xi}$ :

Case 1: Zero frequency intercept:

$z_{S t+s, 1}=[1] '$ with $\delta=\left(\delta_{0}\right)$.

Case 2: Zero frequency intercept with trend:

$z_{S t+s, 2}=[1, S t+s]^{\prime}$ with $\delta=\left(\delta_{0}, \bar{\delta}_{0}\right)^{\prime}$. 
Case 3: Seasonal intercepts:

$$
\begin{aligned}
z_{S t+s, 3}= & {[1, \cos (2 \pi(S t+s) / S), \sin (2 \pi(S t+s) / S), \ldots} \\
& \left.\ldots, \cos \left(2 \pi S^{*}(S t+s) / S\right), \sin \left(2 \pi S^{*}(S t+s) / S\right),(-1)^{S t+s}\right]^{\prime}
\end{aligned}
$$

with $\delta=\left(\delta_{0}, \delta_{1}^{\prime}, \ldots, \delta_{S^{*}}^{\prime}, \delta_{S / 2}^{\prime}\right)^{\prime}, \delta_{k}=\left(\delta_{k, 1}, \delta_{k, 2}\right)^{\prime}, k=1, \ldots, S^{*}=\mathrm{S}$.

Case 4: Seasonal intercepts with zero frequency trend:

$$
z_{S t+s, 4}=\left[z_{S t+s, 3}^{\prime}, S t+s\right]^{\prime} \quad \delta=\left(\delta_{0}, \delta_{1}^{\prime}, \ldots, \delta_{S^{*}}^{\prime}, \delta_{S / 2}^{\prime}, \bar{\delta}_{0}\right)^{\prime}, \delta_{k}=\left(\delta_{k, 1}, \delta_{k, 2}\right)^{\prime}, k=1, \ldots, S^{*}
$$

Case 5: Seasonal intercepts with trends:

$$
z_{S t+s, 5}=\left[z_{S t+s, 3}^{\prime},(S t+s) z_{S t+s, 3}^{\prime}\right]^{\prime}
$$

with $\delta=\left(\delta_{0}, \delta_{1}^{\prime}, \ldots, \delta_{S^{*}}^{\prime}, \delta_{S / 2}^{\prime}, \bar{\delta}_{0}, \bar{\delta}_{1}^{\prime}, \ldots, \bar{\delta}_{S^{*}}^{\prime}, \bar{\delta}_{S / 2}^{\prime}\right)^{\prime}, \delta_{k}=\left(\delta_{k, 1}, \delta_{k, 2}\right)^{\prime},, \bar{\delta}_{k}=\left(\bar{\delta}_{k, 1}, \bar{\delta}_{k, 2}\right)^{\prime} k=1, \ldots, S^{*}$

As shown by Smith and Taylor (1998) and Smith, Taylor and del Barrio Castro (2009), the inclusion of seasonal intercepts allows for tests invariant to the presence of non-zero initial conditions under the null hypothesis of seasonal integration to be obtained, and the inclusion of seasonal intercepts with trends allows for tests invariant to the presence of non-zero initial values and seasonal drifts to be obtained. As will be mentioned later, the deterministic part considered in the seasonal unit root procedures plays an important role in the distribution of the tests.

The overall null hypothesis of seasonal unit roots is $H_{0}: \alpha(L)=1-L^{S}=\Delta_{S}$, hence the time series $y_{S t+s}$ is seasonally integrated. This can be partitioned into the following nulls:

$$
\begin{aligned}
& H_{0,0}: \alpha_{0}=1, \quad H_{0, S / 2}: \alpha_{S / 2}=1 \\
& H_{0, k}: \alpha_{k}=1, \beta_{k}=0 \quad k=1, \cdots, S / 2-1
\end{aligned}
$$

Under $H_{0,0}$ we have a unit root associated with the zero frequency, under $H_{0, S / 2}$ we have a unit root associated with the Nyquist Frequency $(\pi)$. And under $H_{0, k}$ we have a pair of complex conjugate roots associated with seasonal harmonic frequencies $\frac{2 \pi k}{S}$ for $k=1, \ldots, S^{*}=S / 2-1$. The alternative hypothesis is of stationarity at one or more of the zero or seasonal frequencies; that is, $H_{1}=U_{j=0}^{S / 2} H_{1, j}$, where:

$$
\begin{aligned}
& H_{1,0}: \alpha_{0}<1, \quad H_{1, S / 2}: \alpha_{S / 2}<1 \\
& H_{1, k}: \alpha_{k}^{2}+\beta_{k}^{2}<1 \quad k=1, \cdots, S / 2-1
\end{aligned}
$$

It is possible to define a set of filters that remove the presence of unit roots at the zero, Nyquist and seasonal harmonic frequencies $\frac{2 \pi k}{S}$ for $k=1, \ldots, S^{*}=S / 2-1$, as follows:

$$
\Delta_{0}^{0}(L)=\frac{1-L^{S}}{1-L}=\left(1+L+L^{2}+\ldots+L^{S-1}\right)
$$


$\Delta_{S / 2}^{0}(L)=-\frac{1-L^{S}}{1+L}=-\left(1-L+L^{2}-\ldots-L^{S-1}\right)$

$\Delta_{k}^{0}(L)=-\frac{1-L^{S}}{\left(1-2 \cos \left[\omega_{k}\right] L+L^{2}\right)}=-\frac{\sum_{j=0}^{S-1} \sin \left[(j+1) \omega_{k}\right] L^{j}}{\sin \left[\omega_{k}\right]}=$

$=-\left(1-L^{2}\right) \sum_{j \neq k, j=1}^{S^{*}}\left(1-2 \cos \left[\omega_{j}\right] L+L^{2}\right)$

for $k=1, \ldots,(S-1) / 2$.

Following HEGY (1990) and Smith et al. (2009), the regression-based approach for testing for unit roots in $\alpha(L)$ can be developed in two steps. The first step is detrending the data in order to obtain tests that will be invariant to the parameters that characterize the deterministic part $\mu_{S t+s}$. The most popular methods for doing this are OLS detrending (see, for example, HEGY (1990) and Smith et al. (2009)) and GLS detrending (see Rodrigues and Taylor (2007)). In the case of OLS detrending, the resulting detrended time series is obtained from $y_{S t+s}^{\xi}=y_{S t+s}-\hat{\delta}^{\prime} z_{S t+s, \xi}$, where $\hat{\delta}^{\prime}$ is obtained from the OLS regression of $y$ on $z_{\xi}$, with $y$ being a vector with the generic element $y_{S t+s}$ and $z_{\xi}$ is a matrix with generic row element $z_{S t+s, \xi}$. And $\xi$ corresponds to the deterministic part considered. In the case of GLS detrending, the resulting detrended time series is defined as $y_{S t+s}^{\xi}=y_{S t+s}-\hat{\delta}^{\prime} z_{S t+s, \xi}$ and in this case $\hat{\delta}^{\prime}$ is obtained from the OLS regression of $y_{c}$ on $z_{c, \xi}$, where:

$$
\begin{aligned}
& y_{c}=\left(y_{1-S}, y_{2-S}-\alpha_{1}^{c} y_{1-S}, y_{3-S}-\alpha_{1}^{c} y_{2-S}-\alpha_{2}^{c} y_{1-S}, \ldots, y_{0}-\alpha_{1}^{c} y_{-1}-\ldots-\alpha_{S}^{c} y_{1-S}, \Delta_{c} y_{1}, \ldots, \Delta_{c} y_{T}\right)^{\prime} \\
& z_{c, \xi}=\left(z_{1-S, \xi}, z_{2-S, \xi}-\alpha_{1}^{c} z_{1-S, \xi}, z_{3-S, \xi}-\alpha_{1}^{c} z_{2-S, \xi}-\alpha_{2}^{c} z_{1-S, \xi}, \ldots, z_{0, \xi}-\alpha_{1}^{c} z_{1, \xi}-\ldots-\alpha_{S}^{c} z_{1-S, \xi},\right. \\
& \left.\Delta_{c} z_{1, \xi}, \ldots, \Delta_{c} z_{T, \xi}\right)^{\prime}
\end{aligned}
$$

and

$$
\Delta_{c}=\left(1-\bar{\alpha}_{0} L\right)\left(1-\bar{\alpha}_{S / 2} L\right) \prod_{j=1}^{S / 2-1}\left(1-2\left[\alpha_{j} \cos \left(\frac{2 \pi j}{S}\right)\right] L+\bar{\alpha}_{j}^{2} L^{2}\right)=\left(1-\sum_{j=1}^{S} \alpha_{j}^{c} L^{j}\right)
$$

with:

$$
\bar{\alpha}_{0}=1+\frac{c_{0}}{S T}, \quad \bar{\alpha}_{S / 2}=1+\frac{c_{S / 2}}{S T}, \quad \bar{\alpha}_{j}=1+\frac{c_{j}}{S T} \quad j=1,2, \cdots, S / 2-1
$$

Table 1 collects the detrending parameters suggested by Elliot, Rothenberg and Stock (1996), Gregoir (2006) and Rodrigues and Taylor (2007). 
Table 1. The QD detrending parameters

\begin{tabular}{|c|c|c|c|c|c|}
\hline & $\begin{array}{c}\text { Case } 1 \\
\text { Zero frequency } \\
\text { intercept }\end{array}$ & $\begin{array}{c}\text { Case } 2 \\
\text { Zero frequency } \\
\text { intercept with } \\
\text { trend }\end{array}$ & $\begin{array}{c}\text { Case } 3 \\
\text { Seasonal } \\
\text { intercepts }\end{array}$ & $\begin{array}{c}\text { Case } 4 \\
\text { Seasonal } \\
\text { intercepts with } \\
\text { zero frequency } \\
\text { trend }\end{array}$ & $\begin{array}{l}\text { Case } 5 \\
\text { Seasonal } \\
\text { intercepts with } \\
\text { trends }\end{array}$ \\
\hline $\mathrm{c}_{0}$ & -7.00 & -13.5 & -7.00 & -13.5 & -13.5 \\
\hline$c_{k}$ & 0 & 0 & -3.75 & -3.75 & -8.65 \\
\hline $\mathrm{c}_{\mathrm{S} / 2}$ & 0 & 0 & -7.00 & -7.00 & -13.5 \\
\hline
\end{tabular}

Then, using the detrended data obtained from OLS or GLS detrending, the HEGY (1990) approach is based on expanding $\alpha(L)$ around the zero and seasonal frequency unit roots, $\exp ( \pm i 2 \pi j / S), j=0, \ldots, S / 2$, hence the testing equation of the augmented HEGY approach can be written as:

$$
\begin{aligned}
\Delta_{S} y_{S t+s}^{\xi} & =\pi_{0} y_{0, S t+s}^{\xi}+\pi_{S / 2} y_{S / 2, S t+s}^{\xi}+\sum_{j=1}^{S / 2-1}\left(\pi_{1 j} y_{1 j, S t+s}^{\xi}+\pi_{2 j} y_{2 j, S t+s}^{\xi}\right) \\
& +\sum_{j=1}^{k} d_{j} \Delta_{S} y_{S t+s-j}^{\xi}+e_{S t+s, k}^{\xi}
\end{aligned}
$$

where

$$
\begin{aligned}
& y_{0, S t+s}^{\xi}=\Delta_{0}^{0}(L) y_{S t+s-1}^{\xi}=\sum_{i=0}^{S-1} y_{S t+s-i-1}^{\xi} \\
& y_{S / 2, S t+s}^{\xi}=\Delta_{S / 2}^{0}(L) y_{S n+s-1}^{\xi}=\sum_{i=0}^{S-1} \cos [(i+1) \pi] y_{S t+s-i-1}^{\xi} \\
& y_{1 j, S t+s}^{\xi}=-\left[\cos \left(\omega_{j}\right)-L\right] \Delta_{j}^{0}(L) y_{S n+s-i-1}^{\xi}=\sum_{q=0}^{S-1} \cos \left[(q+1) \omega_{j}\right] y_{S t+s-q-1}^{\xi} \\
& y_{2 j, S t+s}^{\xi}=\sin \left(\omega_{j}\right) \Delta_{j}^{0}(L) y_{S t+s-1}^{\xi}=-\sum_{q=0}^{S-1} \sin \left[(q+1) \omega_{j}\right] y_{S t+s-q-1}^{\xi} \\
& j=1, \ldots, S / 2-1 .
\end{aligned}
$$

Under the HEGY approach, the possible presence of serial correlation in the innovation $u_{S t+s}$ in equation (1) is accommodated by augmenting regression (9) by adding lags of $\Delta_{S} y_{S t+s}^{\xi}$, approximating the possible serial correlation in $u_{S t+s}$ with a finite $\operatorname{AR}(k)$ process. As show by del Barrio Castro et al. (2014), this approach is valid for innovations that are allowed to follow a general linear process, and hence $u_{S t+s}$ allows 
for causal and invertible $\operatorname{ARMA}(p, q)$ representation. See del Barrio Castro et al. (2014) for details regarding assumptions.

As shown in HEGY (1990) and Smith et al. (2009), testing $H_{0,0}: \alpha_{0}=1$ and $H_{0, S / 2}: \alpha_{S / 2}=1$ is equivalent to testing $H_{0,0}: \pi_{0}=0$ and $H_{0, S / 2}: \pi_{S / 2}=0$, respectively. Note that the coefficients $\pi_{0}$ and $\pi_{S / 2}$ in equation (8) are associated with the auxiliary variables $y_{0, S t+s}^{\xi}$ and $y_{S / 2, S t+s}^{\xi}$, respectively, and these same variables refer to the unit root at zero and Nyquist frequencies, respectively. In both cases, the test is carried out using lower tailed regression $t$-test statistics $t_{0}$ and $t_{s / 2}$.

When testing the pairs of complex conjugates unit roots $H_{0, k}: \alpha_{k}=1, \beta_{k}=0, k=1, \cdots, S / 2-1$, it is equivalent to test $H_{0, k}: \pi_{1 k}=0, \pi_{2 k}=0$, associated with the auxiliary variables $y_{1 j, S t+s}^{\xi}$ and $y_{2 j, S t+s}^{\xi}$. For this purpose, a lower tailed regression $t$-test statistic for $\pi_{1 k}=0$ and a two tailed regression $t$-test statistic for $\pi_{2 k}=0$ are proposed in the original HEGY (1990) paper as well as an upper-tailed regression F-type test to test the joint null hypothesis $H_{0, k}: \pi_{1 k}=0, \pi_{2 k}=0, F_{k}$.

Further, Ghysels et al. (1994) and Smith et al. (2009) consider joint frequency tests, in particular, the $F$-type test for controlling for the presence of any seasonal unit root by checking the hypotheses $H_{0, S / 2}: \pi_{S / 2}=0$ and $H_{0, k}: \pi_{1 k}=0, \pi_{2 k}=0, F_{S E A S}$. Finally, the presence of any unit root is tested jointly by the hypotheses $H_{0,0}: \pi_{0}=0, H_{0, S / 2}: \pi_{S / 2}=0$ and $H_{0, k}: \pi_{1 k}=0, \pi_{2 k}=0, F_{A L L}$.

Burridge and Taylor (2001) and Smith, Taylor and del Barrio Castro (2009) in the case of autoregressive (AR) innovations, del Barrio Castro and Osborn (2011) for moving average (MA) innovations and del Barrio Castro, Osborn and Taylor (2012) in the case of general linear processes, show that if regression (8) is properly augmented, the limiting null distributions of the t-statistics for unit roots at the zero and Nyquist frequencies and joint F-type statistics are pivotal, while those of the t-statistics at the harmonic seasonal frequencies depend on nuisance parameters which are functions of the parameters associated with the process followed by the innovation. Then, in practice using only the t-statistics for unit roots at the zero and Nyquist frequencies is recommended, and using joint F-type statistics is recommended for testing other hypotheses.

As shown in Smith and Taylor (1998) and Smith, Taylor and del Barrio Castro (2009), when there is no deterministic part $\left(\mu_{S t+s}=0\right)$, the distribution of the tests is a function of standard Brownian motions. In the case of OLS detrending, when seasonal intercepts are considered (Case 3 ) the distribution of the tests is a function of demeaned Brownian motions. In the case of a zero frequency intercept (Case 1) only the distribution of the tests associated with the zero frequency is a function of a demeaned Brownian motion. When seasonal intercepts with trends (Case 5) are included, the distribution of the tests is a function of demeaned and detrended Brownian motions. And finally, if seasonal intercepts with a zero frequency trend (Case 4) are considered, the distribution of all the tests is a function of demeaned Brownian motions except the zero frequency test which is a function of demeaned and detrended Brownian motion. Finally, when GLS detrending is considered, the limit distribution of the statistics with standard Brownian motions are replaced by their relevant local GLS detrended analogues; see Theorem 5.1 of Rodrigues and Taylor (2007, pp. 559-560). See also the tables in the appendix.

\section{3.- Simulations experiments}


The seminal papers of MacKinnon $(1994,1996)$ developed the methodology for obtaining numerical distribution functions for the (zero frequency) unit root test statistics. This methodology implies extensive computation, as well as huge matrices of results. MacKinnon (1996) himself reports several months of computing time and around 20 thousand estimated coefficients. Harvey and van Dijk (2006) and DiazEmparanza (2014) apply this methodology to the case of seasonal unit root tests considering only OLS detrending.

Here, we also use the methodology of simulation experiments as described in Mackinnon (1996) but applied to the case of seasonal unit roots; we also consider both OLS and GLS detrending and analyze a wider set of specifications for the deterministic part.

In order to obtain results which can be fitted to response surface functions we need to run the Monte-Carlo Experiment discussed hereafter, based on the following data generating process:

$$
\left(1-L^{S}\right) y_{S t+s}=u_{S t+s}, s=1-S, \ldots, 0, t=1,2, \ldots, T
$$

with zero initial values $y_{0+s}=0, s=1-S, \ldots, 0$, and where for quarterly data $S=4$ and for monthly data $S=12$. We use 200.000 replications, and instead of repeating each experiment 50 times as in MacKinnon (1995), we do it 48 times because we use parallel computing with 12 threads, and 48 is the closest aliquot number. We consider 27 effective sample sizes of $T$ (number of years). Density of $T$ is higher for the small samples due to the decreased power of the test. The selected values of $T$ are: $9,10,11,12,13,14,16,18$, $19,21,23,26,28,31,34,38,41,45,50,55,61,67,73,81,89,100$ and 150 . Equations (8) and (9) without augmentation (that is, with $k=0$ ) are fitted to process (10), and the value obtained for the t-ratio and F-type statistics of the HEGY procedure are stored using OLS and GLS detrending. For OLS detrending, we consider six sets of deterministic term specifications, the five cases detailed in section 2 plus the case of no deterministic part. And in the case of GLS detrending we consider the five cases mentioned in section 2 .

Thus, we performed a total of 28,512 simulation experiments with 200,000 replications each. The number of experiments is the product of 48 repetitions, 27 sample sizes, five and six different specifications for the deterministic part and two values for $S$. It took around 4 weeks of computing time and $250 \mathrm{~GB}$ of disk space to store the results. The simulations were performed on Intel ${ }^{\circledR}$ Xeon ${ }^{\circledR}$ CPU E5-2470.

A replication experiment is a good example to highlight the power of parallel computing. Each experiment may be computed separately, which is why we computed 12 experiments at once. Using Amdahl's formula, it is possible to estimate the expected improvement in computing time using the parallelization.

$$
T_{C}=\frac{1}{(1-P)+\frac{P}{C}}
$$

Where $T_{C}$ is the time improvement, $C$ is the number of cores used, and $P$ is the percentage of the algorithm that can be parallelized, and which is calculated as the number of code lines under threading divided by the total number of lines; it is equal to $79.4 \%$ in our case. In total, we made a 3.67 times improvement due to parallel computing.

\section{1.- Response surface estimation}

Gathering the results of all the simulations (the most extensive part of the study) and following Mackinnon (1996), we proceed to estimate the regressions for the quantiles for each test statistic. For each experiment with 200,000 replications we estimate 221 quantiles, which are: $.0001, .0002, .0005, .001, .002, \ldots, .010$, $.015, \ldots . .985, .990, .991, \ldots, .999, .9995, .9998, .9999$. These quantiles for a given $S$ and a given specification 
of the deterministic terms, are denoted as $q^{p}\left(T_{i}\right)$, where $T_{i}$ is the sample size of the $i^{\text {th }}$ experiment, $p$ is the quantile and $i=1, \ldots, 1296$, represents the 27 different samples sizes and 48 repetitions. These quantiles are used as the dependent variable of the following response surface equation:

$$
q^{p}\left(T_{i}\right)=\theta_{\infty}^{p}+\theta_{1}^{p} T_{i}^{-1}+\theta_{2}^{p} T_{i}^{-2}+\theta_{3}^{p} T_{i}^{-3}+\varepsilon_{i}
$$

Note that the explanatory variables of the previous equation are three negative power functions of the sample size. ${ }^{4}$ Equation (12) is fitted for the 221 quantiles, for each possible specification of the deterministic part (with OLS and GLS detrending), for each test of the HEGY procedure and finally for quarterly and monthly data.

In order to put model (12), that is, $q^{p}=Z \theta+\varepsilon$ in matrix notation, we follow Mackinnon (1996) and use a modification of the GMM estimator of Cragg (1983) as an appropriate way to deal with the presence of heteroscedasticity in the errors:

$$
\tilde{\theta}=\left(Z^{\prime} W\left(W^{\prime} \tilde{\Omega} W\right)^{-1} W^{\prime} Z\right)^{-1} Z^{\prime} W\left(W^{\prime} \tilde{\Omega} W\right)^{-1} W^{\prime} q^{p}
$$

where $W$ is a matrix of 27 zero-one dummy variables, that is, the first column takes a value of 1 when $T_{\mathrm{i}}=9$, the second one takes a value of 1 when $T_{i}=10, \ldots ; Z$ is a matrix that collects the regressors of equation (12); and $\widetilde{\Omega}$ is a diagonal matrix in which the elements of the principal diagonal are the squares of a fitted endogenous variable obtained from a regression of the absolute value of the residuals from an OLS regression of $q^{p}$ on $W$, on a constant and $1 / T$.

Figure 1 shows the cumulative numerical distribution function of two test statistics for two fixed sample sizes. The deterministic term specification is seasonal intercepts. The graph on the left hand side represents the distribution of $t_{0}$ statistics. The sample size is denoted by $T$. A curve that corresponds to a 9-year sample size is associated with more negative values than a curve that corresponds to 150 years, which means that hypothesis $\mathrm{H}_{0,0}$ is harder to reject for smaller samples. The graph on the right represents the distribution of F-type test statistics for checking the overall null hypothesis.

\footnotetext{
${ }^{4}$ For the $F_{k}$ tests $(k=1,2 \ldots, 5)$; in the monthly case we have 6480 observations. In fact, there are five F-type tests with the same asymptotic distribution, thus we used the test results of the entire simulation in order to increase the efficiency of estimates. The resulting numerical distribution is valid for testing all five $H_{0, k}$ hypothesis.
} 
Figure 1. The cumulative numerical distribution of $t_{0}$ and F-all statistics with fixed sample sizes.

$t_{0}$

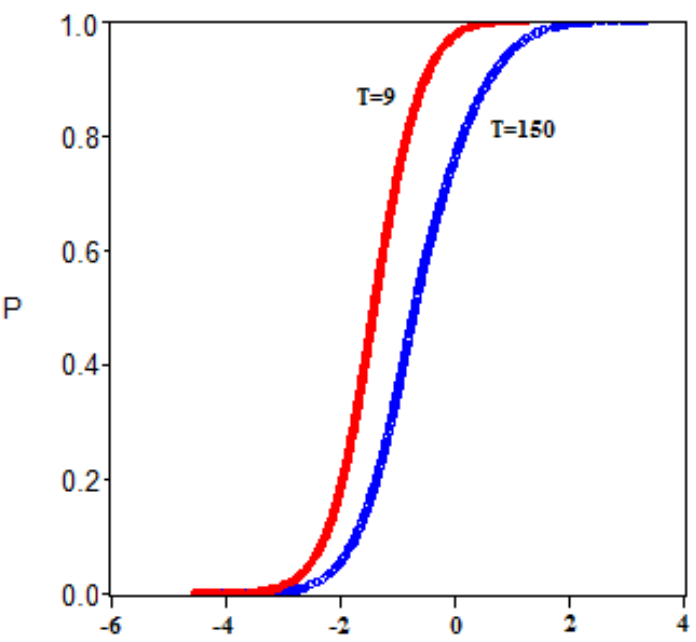

$\mathrm{F}_{\mathrm{ALL}}$

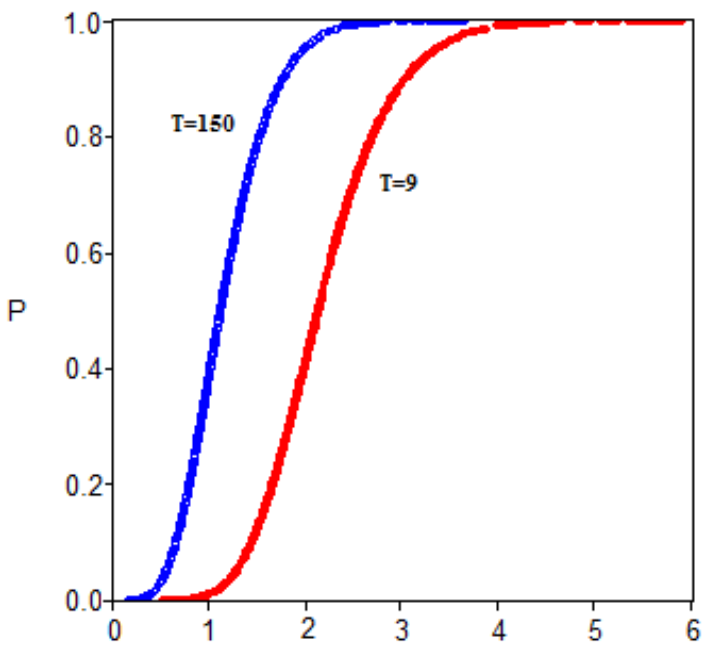

Note: $\mathrm{T}$ is a sample size in years. The deterministic term considers seasonal intercepts.

Another way to look at the data in hand is to fix the $p$-value and plot the distribution depending on $T$. Figure 2 shows the quantiles that correspond to $1 \%, 5 \%$ and $10 \%$ significance levels of the $p$-value. The graph on the left is associated with $t_{0}$ test statistics and the graph on the right is associated with $\mathrm{F}_{\mathrm{ALL}}$ test statistics. Dots represent the actual numerical distribution of test statistics, and the connecting lines are quantile functions constructed according to equation (12).

Figure 2. Quantile distributions with fitted quantile functions for $t_{0}$ and $F_{A L L}$ tests.

$t_{0}$

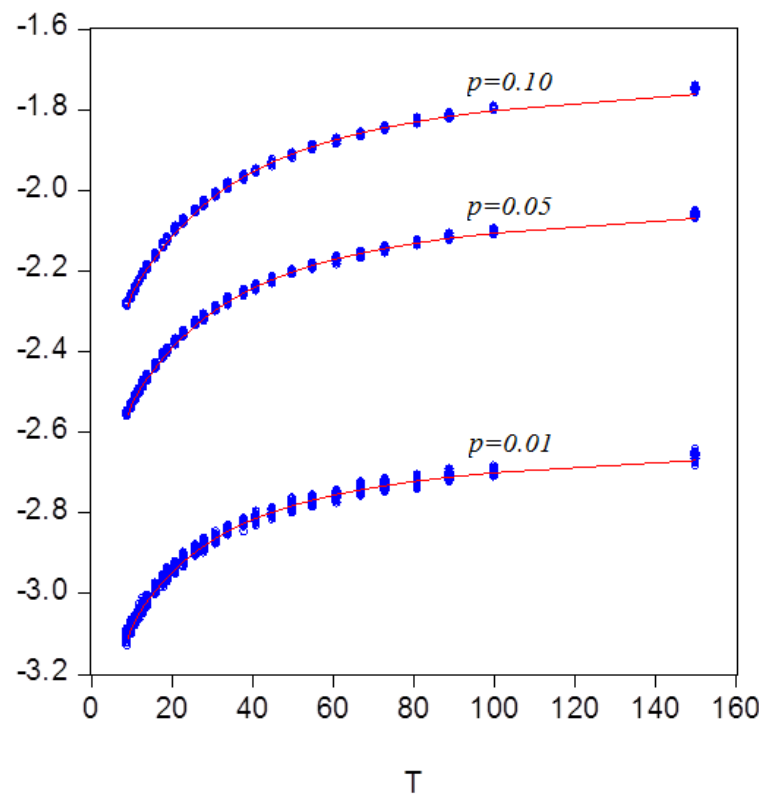

$\mathrm{F}_{\mathrm{ALL}}$

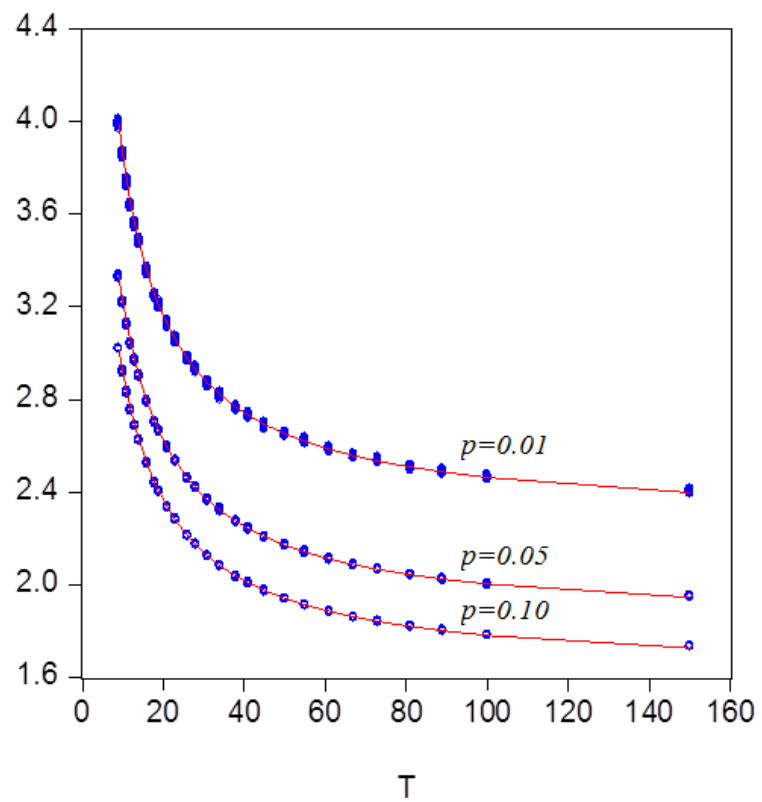

Note: Quantiles correspond to the $p$-levels equal to $1 \%, 5 \%$ and $10 \%$. The deterministic term considers seasonal intercepts. $T$ is a sample size in years. 
In the appendix we report the response surface coefficients calculated according to equation (12) with $p$ values equal to $1 \%, 5 \%$ and $10 \%$. These functions are associated with the line curves in Figure 2 . Tables 2 to 5 report the coefficients for monthly and quarterly frequencies with OLS and GLS detrending. In particular, Tables 2 and 3 display the results when GLS detrending is used for monthly and quarterly data, respectively, and tables 4 and 5 show the equivalent results under OLS detrending.

Note that the first parameter $\theta_{\infty}^{p}$ is the $p^{\text {th }}$ quantile of the asymptotic distribution. And, it is possible to check, for example, that the estimated values of $\theta_{\infty}^{p}$ in table 2 case 1 (with GLS detrending) and table 4 with no deterministic part (with OLS detrending) report basically the same values as expected. Note also that in table 2 we obtain the same values for $\theta_{\infty}^{p}$ for cases 1 and 3 . Or, the fitted value of $\theta_{\infty}^{p}$ for $t_{0}$ for case 2 in table 2 is the same as those observed for $t_{0}$ and $t_{s / 2}$ for case 4 in table 2 . Hence the previous examples, as well as others, show that the reported results in tables 2 to 5 support the theoretical results regarding the distribution of the tests of the HEGY procedure reported in, for example, Rodrigues and Taylor (2007) and del Barrio Castro, Osborn and Taylor (2012).

The eighth column of the table shows the $\mathrm{R}^{2}$ statistics for the corresponding response surfaces. Most of the values are above 0.90 . However, some of the cases are quite low. After careful evaluation of such cases we found that the response surface is less dependent on the sample size. For instance, in Table 3 (GLS detrending and quarterly data), the $\mathrm{R}^{2}$ for the $\mathrm{F}_{\text {SEAS }}$ type of test, case 1 , we observe that the determination coefficient ranges from 0.95 to 0.22 . Figure $2 \mathrm{~A}$ shows the quantile distribution together with the response surface for the $F_{\text {SEAS }}$ type of test. As it can be seen, the low $R^{2}$ is due to the low variation of the quantiles as a function of the sample size.

Figure 2A. Quantile distribution with fitted quantile functions for $F_{\text {SEAS }}$ type of test, GLS detrending, case 1, quarterly data

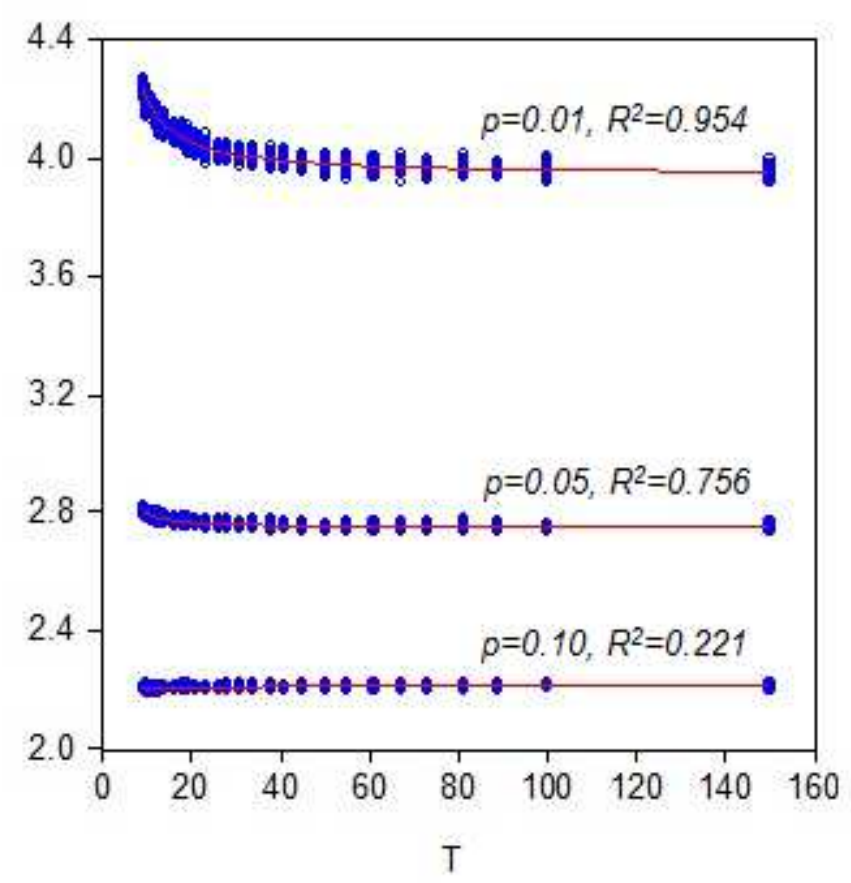

Moreover, in table 6 in the appendix the critical values obtained from the response surfaces with low $R^{2}$ are compared with the corresponding critical values tabulated in previous studies (Smith and Taylor, 1998; Franses and Hobijn, 1997). Both the values from the previous studies and those calculated from the response surfaces exhibit only small changes as the sample size grows. Moreover, the tabulated critical 
values sometimes show local maximums or minimums as sample size increases which seems contrary to the expected evolution of the distribution. These results indicate that even in the case that the $R^{2}$ is low for a given response surface, the critical values computed with this function are more accurate that the previously tabulated ones.

\section{2.- Local approximations for $p$-values}

The resulting 221 estimated response surfaces for the quantiles return the estimated quantile value for any sample size and for a given type of test and specification of the deterministic term. These estimates can be used to obtain approximate $p$-values for any value of the test statistic. As in MacKinnon (1996), we use interpolation to estimate the $p$-value of a particular value of the reported test statistic. The first step is to locate the closest quantiles. The sample size is introduced into 221 response surfaces and the corresponding critical values are obtained. Then, the test statistic is compared sequentially with every critical value and the four closest quantiles are identified: two from above and two from below. After obtaining the closest values, an interpolation function using a polynomial of order three is used. Then, the test statistics of the HEGY seasonal unit root test are introduced into the estimated polynomial, and the $p$ value is reported. The local approximation method to obtain the $p$-values and the estimates of the response surfaces are implemented in a GAUSS ${ }^{\mathrm{TM}}$ library and are available from the authors upon request.

\section{3.- Comparison of our results with the previous studies}

Having the response surface estimates and a method with which to obtain $p$-values by local approximation, we proceed to compare our results with those of previous studies. One of the ways to do so is to use the critical values reported by HEGY (1990), Franses and Hobijn (1997), Smith and Taylor (1998) and Rodrigues and Taylor (2007) as the input for our local approximation method and then compare the resulting $p$-values with the reported ones. Of course, some small discrepancies are expected between results given that they come from estimations and are subject to randomness.

Table 7 reports the critical values that differ from the previous studies by less than two decimal places. All other cases are different out to the third decimal place or more. The first column of the table reports the sample size in quarters or months. The second column reports the type of test: $t_{0}, t_{S / 2}, F_{K}, F_{S E A S}$ or $F_{A L L}$. In the third column, deterministic terms are represented by CASE 1 to 5 , and each of these cases corresponds to the cases described in the methodological part; none stands for no deterministic terms. The next two columns correspond to nominal size and critical values reported in the previous papers. Then, we calculate the $p$-value for the critical value reported (" $p$-value, calculated" column) and show the difference between this computed $p$-value and the reported one. The table is sorted by descending $p$-value difference. Finally, the last column of Table 7 suggests our critical value for the corresponding test statistics based on 9,6 million replications for each sample size (that is 200,000 replications in 48 simulation experiments for each T). The authors of the original tables perform from 24 to 100 thousands replications per sample size. The extensive number of simulations in our research implies more accurate estimates.

Originally, the paper of HEGY (1990) works with quarterly data. The authors use 24,000 Monte Carlo replications and report $t_{\pi 1}, t_{\pi 2}, t_{\pi 3}, t_{\pi 4}$ and $F_{\pi 3, \pi 4}$ critical values. In our study we refer to these statistics as $t_{0}$, $t_{5 / 2}$ and $F_{k}$, and we do not report $t_{\pi 3}$ and $t_{\pi 4}$ statistics. We checked the quantiles that correspond to $5 \%$ and $10 \%$ significance levels. Table 7 reports the 14 of a total of 120 cases where the difference is bigger than 0.02. In the other $88,3 \%$ of cases the difference is smaller.

Franses and Hobijn (1997) work with frequencies $S=2, S=4, S=6$ and $S=12$, so we use $S=4$ and $S=12$ in order to compare results. The authors apply 25,000 replications and report the same five types of tests. For the 
quarterly case, the results matched $99.5 \%$ of the time (difference observed in only 2 of 400 cases) and for the monthly case, the results matched $99 \%$ of the time (difference observed in 4 of 400 cases).

Smith and Taylor (1998) report the critical value for quarterly data at $1 \%, 2.5 \%, 5 \%$ and $10 \%$ significance levels. The deterministic terms considered are seasonal intercepts with seasonal trends. The authors use 40,000 Monte Carlo replications and report $t_{0}, t_{S / 2}, F_{K}, F_{S E A S}$ and $F_{A L L}$ statistics. The results of their study perfectly match with our results and none of the 100 critical values differ significantly.

Rodrigues and Taylor (2007) report the critical values for seasonal unit root tests with GLS detrending based on 100,000 replications. The authors consider quarterly data and perform the same five types of tests that we do. Only in 8 of 360 total cases do the $p$-values differ to the second decimal place. The other $97,8 \%$ of results differ from the third decimal place or more.

The studies of MacKinnon (1996) and Diaz-Emparanza (2014) report the same response surface functions and routines for computing $p$-values as we do. So, one possible way to compare our results is to introduce the same statistics into the reported functions and compare the $p$-values.

The paper of Diaz-Emparanza (2014) reports response surfaces for HEGY seasonal unit root test for given periodicity as well as $p$-values. The package of functions is developed under the Gretl program, and it is available online. The deterministic terms considered are: only a constant, constant with linear trend, constant with seasonal dummies, and seasonal dummies with linear trend. It is possible to compare $p$ values for monthly and quarterly frequencies using all five types of tests.

After introducing the same test statistics into two functions, we obtain very similar results for $t_{0}, t_{s / 2}$ and $F_{K}$ types of tests. The $p$-values for the $\mathrm{F}_{\mathrm{SEAS}}$ and $\mathrm{F}_{\mathrm{ALL}}$ statistics are significantly different. That is why we perform cross verification with the critical values published in previous studies. These statistics are only present in the paper of Franses and Hobijn (1997), as HEGY (1990) do not report $F_{\text {SEAS }}$ and $F_{\text {ALL }}$ types of statistics; Smith and Taylor (1998) report only the critical values for the tests with seasonal intercepts and seasonal trends, which is not covered by Diaz-Emparanza (2014). Finally, Rodrigues and Taylor (2007) report the case with GLS detrending which are not accounted for by Diaz-Emparanza (2014). Table 8 shows the results of this cross verification exercise. Here, we report only the results for the $10 \%$ quantile of the largest sample size, which is 40 years in the tables of Franses and Hobijn (1997.

Table 8 demonstrates that there is a significant divergence of results between Diaz-Emparanza (2014) on one hand, and Franses and Hobijn (1997) and our study on the other. This divergence concerns only the $\mathrm{F}_{\mathrm{SEAS}}$ and $\mathrm{F}_{\mathrm{ALL}}$ types of test statistics and suggests that our response surfaces are more accurate than the ones reported by Diaz-Emparanza (2014) for these two test statistics. The distribution of the other three test statistics is consistent across all studies.

\section{4.- Empirical example}

Tourism arrivals to summer destinations are highly influenced by seasonality. In this part, we analyze airport passenger arrivals from Germany to Mallorca, Spain. The island is considered a "sun and sea" destination with high peaks during the summer period and troughs during the winter. The observation period includes data from January, 1980 through April, 2014, that is 412 months. Before testing for the presence of seasonal unit roots, we apply a natural logarithm in order to reduce heteroscedasticity of the data in hand (Figure 3).

Figure 3. Logarithm of airport passenger arrivals from Germany to Palma de Mallorca, Spain. 


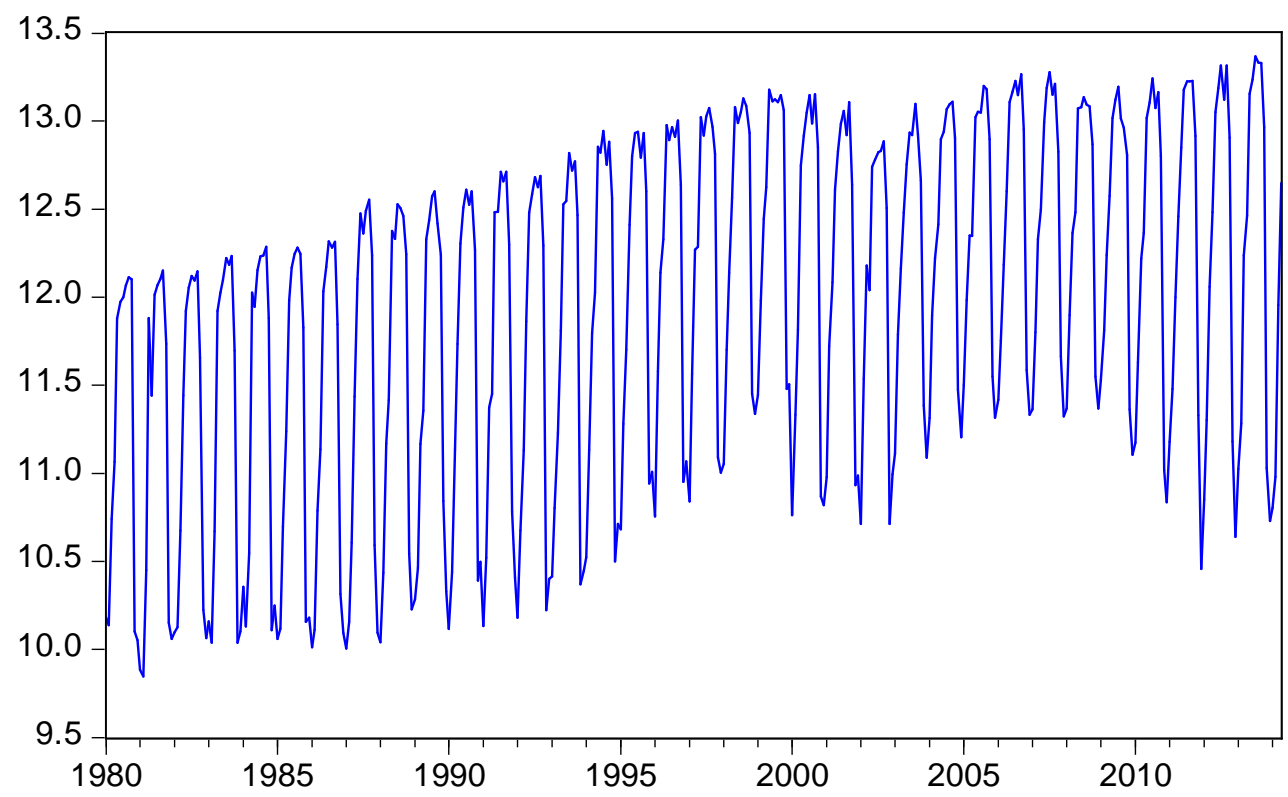

Note: Observation period: January, 1980 - April, 2014.

In Table 9 we report the results of HEGY seasonal unit root test with GLS detrending for the data considered. The test statistics are reported together with corresponding $p$-values. We consider three cases of deterministic terms: seasonal intercepts, seasonal intercepts with zero frequency trend and seasonal intercepts with trends. The optimal autoregressive order is estimated by sequentially dropping the last lag until a $10 \%$ significance level is reached. The maximal lag for testing is calculated as the integer part of $12(N / 100)^{1 / 4}$, where $\mathrm{N}$ is the number of observations (equal to 412 ). The optimal lag estimated after sequential testing is equal to 13 for all three cases. 
Table 9. Results of the HEGY seasonal unit root test with GLS detrending applied to airport passenger arrivals to Palma de Mallorca, Spain.

\begin{tabular}{|l|c|c|c|c|c|c|}
\hline & \multicolumn{2}{|c|}{ Seasonal intercepts } & \multicolumn{2}{c|}{$\begin{array}{c}\text { Seasonal intercepts } \\
\text { and zero freq. trend }\end{array}$} & \multicolumn{2}{c|}{$\begin{array}{c}\text { Seasonal intercepts } \\
\text { and trends }\end{array}$} \\
\hline & Value & Prob. & Value & Prob. & Value & Prob. \\
\hline $\mathrm{t}_{0}$ & -0.555 & $\mathbf{0 . 7 7 2}$ & -1.308 & $\mathbf{0 . 8 6 7}$ & -1.284 & $\mathbf{0 . 8 9 1}$ \\
\hline $\mathrm{t}_{\mathrm{S} / 2}$ & -2.967 & $\mathbf{0 . 0 0 7}$ & -2.973 & $\mathbf{0 . 0 0 7}$ & -3.217 & $\mathbf{0 . 0 4 2}$ \\
\hline $\mathrm{F}_{\pi / 6}$ & 0.895 & $\mathbf{0 . 5 6 4}$ & 0.947 & $\mathbf{0 . 5 4 2}$ & 2.676 & $\mathbf{0 . 7 7 5}$ \\
\hline $\mathrm{F}_{\pi / 3}$ & 3.766 & $\mathbf{0 . 0 4 4}$ & 3.865 & $\mathbf{0 . 0 4 0}$ & 7.065 & $\mathbf{0 . 0 7 3}$ \\
\hline $\mathrm{F}_{\pi / 2}$ & 3.499 & $\mathbf{0 . 0 5 7}$ & 3.271 & $\mathbf{0 . 0 7 1}$ & 6.090 & $\mathbf{0 . 1 4 1}$ \\
\hline $\mathrm{F}_{2 \pi / 3}$ & 6.657 & $\mathbf{0 . 0 0 3}$ & 6.676 & $\mathbf{0 . 0 0 3}$ & 10.411 & $\mathbf{0 . 0 0 6}$ \\
\hline $\mathrm{F}_{5 \pi / 6}$ & 3.493 & $\mathbf{0 . 0 5 7}$ & 3.397 & $\mathbf{0 . 0 6 3}$ & 6.386 & $\mathbf{0 . 1 1 6}$ \\
\hline $\mathrm{F}_{\mathrm{SEAS}}$ & 4.248 & $\mathbf{0 . 0 0 0}$ & 4.224 & $\mathbf{0 . 0 0 0}$ & 7.241 & $\mathbf{0 . 0 0 2}$ \\
\hline $\mathrm{F}_{\mathrm{ALL}}$ & 3.922 & $\mathbf{0 . 0 0 0}$ & 4.017 & $\mathbf{0 . 0 0 0}$ & 6.793 & $\mathbf{0 . 0 0 5}$ \\
\hline
\end{tabular}

Note: Deterministic terms are: constant with seasonal intercepts, seasonal intercepts with linear trend and seasonal intercepts with seasonal trends. AR order is equal to 13. Effective sample size is equal to 387.

According to the results shown in the previous table, unit roots were found at the zero and $\pi / 6$ frequencies, which correspond to long-run and one-year seasonality, respectively. In all three cases which include deterministic terms, both hypotheses $\mathrm{H}_{0,0}$ and $\mathrm{H}_{0,1}$ cannot be rejected at any usual significance value. The seasonal unit root hypothesis can be rejected at frequencies $\pi / 2$ and $5 \pi / 6$ at a $10 \%$ significance level according to the test with seasonal intercepts as well as seasonal intercepts with a linear trend, but not when seasonal trends are included. For the $\pi$ frequency, which corresponds to a two-month cycle, the unit root hypothesis is rejected at a $1 \%$ significance level when no seasonal trends are included but only at a $5 \%$ significance level when they are included. The pair of complex unit roots at the $\pi / 3$ frequency, has a $p$-value around $4 \%$ for the two first specifications of the deterministic terms, so the presence of these unit roots is rejected at the $5 \%$ but not at the $1 \%$ significance level; when seasonal trends are introduced, the null hypothesis is rejected at a $10 \%$ but not at a $5 \%$ significance level. Finally, the hypothesis of unit roots associated with the $2 \pi / 3$ frequency, the null hypothesis of all seasonal unit roots and the null hypothesis of the 12 unit roots are all rejected at a $1 \%$ significance level for the three specifications of the deterministic terms.

\section{5.- Conclusions}

This research focuses on seasonal unit root testing and extends the response surface analysis to the context of GLS detrending. Previous studies of Harvey and van Dijk (2006) and Diaz-Emparanza (2014) deal only with the response surfaces with OLS detrending in HEGY seasonal unit root test. The present paper is aimed at handling the case of response surfaces and $p$-values for the HEGY test with GLS detrending for monthly and quarterly data.

Validation tests, which compare the results of our investigation with those of previous studies, are undertaken. Most of the results of previous studies are consistent with this study. In some cases, where the difference is significant, we suggest corrected critical values. 
As a result of this investigation we generated a Gauss library that reports $p$-values for particular $t$ and $F$ test statistics depending on sample size, deterministic terms and frequency of the data. Users can find the Gauss code in the supplementary material of this article.

The empirical application of the suggested methodology to passenger arrivals in Mallorca, shows strong evidence of unit roots at zero and one-cycle-per-year frequency as well as strong evidence that not all the seasonal unit roots are present simultaneously.

\section{Acknowledgements}

Tomas del Barrio Castro and Andreu Sansó knowledge financial support from Spanish Ministerio de Educación, Cultura y Deporte under grant ECO2014-58991-C3-3-R.

\section{References}

Beaulieu, J.J., Miron, J.A. (1993). Seasonal unit roots in aggregate US data. Journal of Applied Econometrics $55,305-328$.

Burridge, P. and Taylor A.M.R. (2001). On the Properties of Regression-Based Tests for Seasonal Unit Roots in the Presence of Higher-Order Serial Correlation. Journal of Business \& Economic Statistics 19, 374-379.

del Barrio Castro, T., and Osborn D.R.(2011) HEGY Tests in the Presence of Moving Averages. Oxford Bulletin of Economics and Statistics 73, 691-704.

del Barrio Castro, T., Osborn, D. R., Taylor, A. M. R. (2012). On augmented HEGY tests for seasonal unit roots. Econometric Theory 28, 1121-1143.

del Barrio Castro, T., Osborn, D.R., Taylor, A.M.R. (2016) The Performance of Lag Selection and Detrending Methods for HEGY Seasonal Unit Root Tests. Econometric Reviews Forthcoming.

Diaz-Emparanza, I. (2014). Numerical distribution functions for seasonal unit root tests. Computational Statistics and Data Analysis 76, 237-247.

Cragg, J.G. (1983). More efficient estimation in the presence of heteroscedasticity of unknown form. Econometrica 58, 751-763.

Elliott, G., Rothenberg, T.J. and Stock, J.H. (1996). Efficient tests for an autoregressive unit root. Econometrica 64, 813-836.

Franses, P.H., Hobijn, B. (1997). Critical values for unit root tests in seasonal time series, Journal of Applied Statistics 24, 25-48.

Harvey, D.I., van Dijk, D. (2006). Sample size, lag order and critical values of seasonal unit root tests. Computational Statistics \& Data Analysis 50, 2734-2751.

Hylleberg, S., R. F. Engle, C. W. J. Granger, and B. S. Yoo. (1990). Seasonal integration and cointegration. Journal of Econometrics 44, 215-238.

MacKinnon, James G. (1994). Approximate Asymptotic Distribution Functions for Unit-Root and Cointegration Tests. Journal of Business \& Economic Statistics 12, 167-76. 
MacKinnon, James G. (1996). Numerical Distribution Functions for Unit Root and Cointegration Tests. Journal of Applied Econometrics 11, 601-18.

Rodrigues, P.M.M., Taylor, A.M.R. (2007). Efficient tests of the seasonal unit root hypothesis. Journal of Econometrics 141, 548-573.

Smith, R.J., Taylor, A.M.R. (1998). Additional critical values and asymptotic representations for seasonal unit root tests. Journal of Econometrics 85, 269-288.

Smith, R.J. , A.M.R. Taylor \& T. del Barrio Castro (2009) Regression-Based Seasonal Unit Root Tests. Econometric Theory 25, 527-560.

Smith, R.J. \& A.M.R. Taylor (1999) Likelihood ratio tests for seasonal unit roots. Journal of Time Series Analysis 20, 453-476.

Taylor A.M.R. (1998) Testing for Unit Roots in Monthly Time Series. Journal of Time Series Analysis 19, 3, 349-368. 


\section{Appendix}

Table 2: Quantile coefficients for monthly data, $p=1 \%, 5 \%$ and $10 \%$, case of GLS detrending

\begin{tabular}{|c|c|c|c|c|c|c|c|c|}
\hline Deter & Type & $\begin{array}{l}\text { Nominal } \\
\text { size }\end{array}$ & $\theta_{\infty}^{p}$ & $\theta_{1}^{p}$ & $\theta_{2}^{p}$ & $\theta_{3}^{p}$ & $\mathrm{R}^{2}$ & $\hat{\sigma}_{\varepsilon}$ \\
\hline \multirow{15}{*}{ CASE 1} & \multirow{3}{*}{$t_{0}$} & 0.01 & -2.6064538 & -10.175621 & 107.06159 & -402.02016 & 0.9926 & 0.0079 \\
\hline & & 0.05 & -1.9928579 & -12.360973 & 127.92231 & -477.93486 & 0.9976 & 0.0056 \\
\hline & & 0.10 & -1.6750552 & -13.950681 & 143.98809 & -538.39363 & 0.9982 & 0.0054 \\
\hline & \multirow{3}{*}{$t_{S / 2}$} & 0.01 & -2.565369 & 1.0884361 & -2.5664519 & 12.626518 & 0.9308 & 0.0076 \\
\hline & & 0.05 & -1.9399909 & 0.8874135 & -0.833552 & 5.3743644 & 0.9732 & 0.0042 \\
\hline & & 0.10 & -1.6159129 & 0.7730544 & -0.565721 & 4.4067282 & 0.9789 & 0.0033 \\
\hline & \multirow{3}{*}{$\mathrm{F}_{\mathrm{K}}$} & 0.01 & 4.7332408 & -2.6292837 & -1.6384555 & 15.6802 & 0.9248 & 0.0223 \\
\hline & & 0.05 & 3.1100621 & -2.0903709 & -2.0046105 & 16.114836 & 0.9766 & 0.0098 \\
\hline & & 0.10 & 2.4080405 & -1.7772591 & -0.7755729 & 7.3328665 & 0.9838 & 0.0068 \\
\hline & \multirow{3}{*}{$\mathrm{F}_{\mathrm{SEAS}}$} & 0.01 & 2.3426785 & 0.4280839 & -4.0327865 & 23.752202 & 0.5580 & 0.0064 \\
\hline & & 0.05 & 1.8781229 & -0.1924286 & -0.8683397 & 5.3513218 & 0.8307 & 0.0031 \\
\hline & & 0.10 & 1.6547904 & -0.2877829 & -1.660114 & 8.7904756 & 0.9599 & 0.0023 \\
\hline & \multirow{3}{*}{$\mathrm{F}_{\mathrm{ALL}}$} & 0.01 & 2.2801347 & 3.5575784 & -20.034165 & 55.871893 & 0.9895 & 0.0061 \\
\hline & & 0.05 & 1.8413546 & 2.8052868 & -18.320792 & 46.396554 & 0.9943 & 0.0030 \\
\hline & & 0.10 & 1.6302099 & 2.5580081 & -18.33629 & 46.626318 & 0.9954 & 0.0022 \\
\hline \multirow{15}{*}{ CASE 2} & \multirow{3}{*}{$t_{0}$} & 0.01 & -3.4304315 & -7.4282461 & 91.886777 & -356.69718 & 0.9769 & 0.0071 \\
\hline & & 0.05 & -2.8781125 & -8.4054363 & 104.26608 & -402.18423 & 0.9923 & 0.0045 \\
\hline & & 0.10 & -2.5934679 & -9.1778755 & 114.42316 & -445.30801 & 0.9944 & 0.0042 \\
\hline & \multirow{3}{*}{$t_{S / 2}$} & 0.01 & -2.5646271 & 0.7722459 & 0.3960046 & -2.0871711 & 0.9020 & 0.0078 \\
\hline & & 0.05 & -1.9396988 & 0.6585131 & 1.0901346 & -4.1652911 & 0.9636 & 0.0042 \\
\hline & & 0.10 & -1.6155446 & 0.572219 & 1.1731581 & -4.6940397 & 0.9706 & 0.0033 \\
\hline & \multirow{3}{*}{$\mathrm{F}_{\mathrm{K}}$} & 0.01 & 4.7325103 & -2.8332203 & 2.146207 & 6.5769371 & 0.8913 & 0.0262 \\
\hline & & 0.05 & 3.1102995 & -2.2223455 & 0.3914827 & 7.1689207 & 0.9629 & 0.0122 \\
\hline & & 0.10 & 2.4073859 & -1.7890958 & -1.0971038 & 13.233966 & 0.9741 & 0.0085 \\
\hline & \multirow{3}{*}{$\mathrm{F}_{\mathrm{SEAS}}$} & 0.01 & 2.344197 & 0.2426348 & -0.160438 & 7.1934005 & 0.6614 & 0.0064 \\
\hline & & 0.05 & 1.8770934 & -0.1630821 & -1.4027531 & 11.669285 & 0.7809 & 0.0030 \\
\hline & & 0.10 & 1.6550325 & -0.3489925 & -0.5352557 & 5.8125377 & 0.9524 & 0.0023 \\
\hline & \multirow{3}{*}{$\mathrm{F}_{\mathrm{ALL}}$} & 0.01 & 2.5458633 & 5.4555905 & -48.924177 & 195.25074 & 0.9908 & 0.0065 \\
\hline & & 0.05 & 2.085075 & 4.6714437 & -49.067748 & 194.37183 & 0.9943 & 0.0034 \\
\hline & & 0.10 & 1.8627893 & 4.3530181 & -48.705273 & 192.25109 & 0.9947 & 0.0026 \\
\hline \multirow{15}{*}{ CASE 3} & \multirow{3}{*}{$t_{0}$} & 0.01 & -2.6032254 & -10.565431 & 89.99929 & -324.73774 & 0.9964 & 0.0079 \\
\hline & & 0.05 & -1.990071 & -12.720026 & 114.68568 & -416.39375 & 0.9987 & 0.0053 \\
\hline & & 0.10 & -1.6723983 & -14.264588 & 132.26462 & -483.8779 & 0.9989 & 0.0052 \\
\hline & \multirow{3}{*}{$t_{s / 2}$} & 0.01 & -2.6033922 & -10.571855 & 90.11207 & -326.24338 & 0.9966 & 0.0076 \\
\hline & & 0.05 & -1.9882113 & -12.875656 & 117.75139 & -433.64868 & 0.9987 & 0.0053 \\
\hline & & 0.10 & -1.6700677 & -14.477611 & 136.40506 & -506.43205 & 0.9990 & 0.0050 \\
\hline & \multirow{3}{*}{$\mathrm{F}_{\mathrm{K}}$} & 0.01 & 4.7221492 & 22.17452 & -129.9066 & 361.83506 & 0.9959 & 0.0230 \\
\hline & & 0.05 & 3.096573 & 20.490423 & -109.26157 & 251.84211 & 0.9991 & 0.0103 \\
\hline & & 0.10 & 2.3935497 & 19.062754 & -90.431116 & 167.21374 & 0.9995 & 0.0074 \\
\hline & \multirow{3}{*}{$\mathrm{F}_{\mathrm{SEAS}}$} & 0.01 & 2.3262363 & 19.097837 & -44.878795 & 56.146641 & 0.9997 & 0.0075 \\
\hline & & 0.05 & 1.8606476 & 16.958423 & -38.28922 & 16.810367 & 0.9999 & 0.0037 \\
\hline & & 0.10 & 1.639021 & 15.815438 & -33.022949 & -9.2209065 & 0.9999 & 0.0028 \\
\hline & \multirow{3}{*}{$\mathrm{F}_{\mathrm{ALL}}$} & 0.01 & 2.2664664 & 20.290791 & -51.10663 & 72.442815 & 0.9998 & 0.0072 \\
\hline & & 0.05 & 1.8262331 & 18.238574 & -47.567433 & 47.302576 & 0.9999 & 0.0037 \\
\hline & & 0.10 & 1.61578 & 17.136718 & -43.799072 & 28.997292 & 0.9999 & 0.0029 \\
\hline
\end{tabular}

(Continued) 
Table 2. (Continued)

\begin{tabular}{|c|c|c|c|c|c|c|c|c|}
\hline Deter & Type & $\begin{array}{c}\text { Nominal } \\
\text { size }\end{array}$ & $\theta_{\infty}^{p}$ & $\theta_{1}^{p}$ & $\theta_{2}^{p}$ & $\theta_{3}^{p}$ & R2 & $\hat{\sigma}_{\varepsilon}$ \\
\hline \multirow{15}{*}{ CASE 4} & \multirow{3}{*}{$t_{0}$} & 0.01 & -3.4262229 & -7.9358366 & 72.645255 & -264.86438 & 0.9939 & 0.0069 \\
\hline & & 0.05 & -2.8737864 & -8.9013045 & 89.260973 & -338.73215 & 0.9975 & 0.0044 \\
\hline & & 0.10 & -2.590424 & -9.5647527 & 99.205847 & -380.26877 & 0.9980 & 0.0040 \\
\hline & \multirow{3}{*}{$t_{S / 2}$} & 0.01 & -2.6033096 & -10.851371 & 91.946728 & -337.23634 & 0.9969 & 0.0076 \\
\hline & & 0.05 & -1.9890582 & -12.985181 & 116.53786 & -426.26983 & 0.9988 & 0.0053 \\
\hline & & 0.10 & -1.6704546 & -14.597529 & 135.88504 & -502.82602 & 0.9990 & 0.0051 \\
\hline & \multirow{3}{*}{$\mathrm{F}_{\mathrm{K}}$} & 0.01 & 4.7219074 & 22.132648 & -126.63915 & 356.32214 & 0.9961 & 0.0228 \\
\hline & & 0.05 & 3.0964846 & 20.463844 & -106.4717 & 239.52831 & 0.9990 & 0.0108 \\
\hline & & 0.10 & 2.3940686 & 19.002652 & -86.878466 & 147.08193 & 0.9994 & 0.0084 \\
\hline & \multirow{3}{*}{$\mathrm{F}_{\mathrm{SEAS}}$} & 0.01 & 2.3260625 & 19.106758 & -42.357516 & 44.817087 & 0.9997 & 0.0074 \\
\hline & & 0.05 & 1.860186 & 17.015625 & -37.07035 & 11.463137 & 0.9999 & 0.0039 \\
\hline & & 0.10 & 1.6382999 & 15.895696 & -32.40938 & -12.082042 & 0.9999 & 0.0031 \\
\hline & \multirow{3}{*}{$\mathrm{F}_{\mathrm{ALL}}$} & 0.01 & 2.5298922 & 22.052039 & -73.86684 & 189.47025 & 0.9998 & 0.0072 \\
\hline & & 0.05 & 2.0693866 & 19.9103 & -71.399675 & 168.54082 & 0.9999 & 0.0037 \\
\hline & & 0.10 & 1.8476919 & 18.791946 & -68.234817 & 151.9954 & 0.9999 & 0.0027 \\
\hline \multirow{15}{*}{ CASE 5} & \multirow{3}{*}{$t_{0}$} & 0.01 & -3.4255075 & -10.916232 & 78.735441 & -301.87954 & 0.9981 & 0.0073 \\
\hline & & 0.05 & -2.8735277 & -11.421414 & 93.029268 & -359.18202 & 0.9992 & 0.0045 \\
\hline & & 0.10 & -2.5897606 & -11.918101 & 103.7276 & -405.92011 & 0.9993 & 0.0041 \\
\hline & \multirow{3}{*}{$t_{s / 2}$} & 0.01 & -3.4306407 & -10.619913 & 73.569174 & -276.34133 & 0.9980 & 0.0074 \\
\hline & & 0.05 & -2.8764177 & -11.285219 & 90.881955 & -348.71474 & 0.9992 & 0.0044 \\
\hline & & 0.10 & -2.5927494 & -11.781383 & 101.68756 & -396.43024 & 0.9993 & 0.0040 \\
\hline & \multirow{3}{*}{$\mathrm{F}_{\mathrm{K}}$} & 0.01 & 8.6680306 & 41.175588 & -206.52703 & 763.13099 & 0.9983 & 0.0326 \\
\hline & & 0.05 & 6.5991203 & 39.046128 & -242.56219 & 878.43064 & 0.9993 & 0.0173 \\
\hline & & 0.10 & 5.6375963 & 38.436568 & -261.67489 & 952.63835 & 0.9995 & 0.0137 \\
\hline & \multirow{3}{*}{$\mathrm{F}_{\mathrm{SEAS}}$} & 0.01 & 5.2745442 & 46.189689 & -199.46349 & 862.48093 & 0.9999 & 0.0118 \\
\hline & & 0.05 & 4.6063816 & 43.236638 & -217.73805 & 876.83087 & 0.9999 & 0.0073 \\
\hline & & 0.10 & 4.2719648 & 41.957602 & -226.62313 & 887.03499 & 0.9999 & 0.0064 \\
\hline & \multirow{3}{*}{$\mathrm{F}_{\mathrm{ALL}}$} & 0.01 & 5.1863965 & 47.7039 & -211.37367 & 928.73124 & 0.9999 & 0.0117 \\
\hline & & 0.05 & 4.5515347 & 44.75336 & -231.17955 & 948.01106 & 0.9999 & 0.0076 \\
\hline & & 0.10 & 4.233677 & 43.432724 & -240.63387 & 962.66299 & 0.9999 & 0.0067 \\
\hline
\end{tabular}

Note: CASE 1 to 5 refers to deterministic terms, which are described in the methodological part. 
Table 3: Quantile coefficients for quarterly data, $p=1 \%, 5 \%$ and $10 \%$, case of GLS detrending

\begin{tabular}{|c|c|c|c|c|c|c|c|c|}
\hline Deter & Type & $\begin{array}{l}\text { Nominal } \\
\text { size }\end{array}$ & $\theta_{\infty}^{p}$ & $\theta_{1}^{p}$ & $\theta_{2}^{p}$ & $\theta_{3}^{p}$ & $R^{2}$ & $\hat{\sigma}_{\varepsilon}$ \\
\hline \multirow{15}{*}{ CASE 1} & \multirow{3}{*}{$\mathrm{t}_{0}$} & 0.01 & -2.6017744 & -11.576394 & 103.59152 & -396.9619 & 0.9964 & 0.0084 \\
\hline & & 0.05 & -1.9890882 & -13.271645 & 124.01966 & -460.71773 & 0.9986 & 0.0055 \\
\hline & & 0.10 & -1.6709987 & -14.719768 & 140.0609 & -515.29043 & 0.9989 & 0.0052 \\
\hline & \multirow{3}{*}{$t_{S / 2}$} & 0.01 & -2.5633008 & -0.1433426 & -2.9538673 & 14.146696 & 0.5478 & 0.0085 \\
\hline & & 0.05 & -1.9396597 & 0.2979791 & -3.7835909 & 21.564794 & 0.3821 & 0.0044 \\
\hline & & 0.10 & -1.6154096 & 0.3350189 & -2.5383989 & 13.526894 & 0.7540 & 0.0035 \\
\hline & \multirow{3}{*}{$\mathrm{F}_{\mathrm{K}}$} & 0.01 & 4.7455076 & 0.0883917 & 9.2387492 & -4.5591302 & 0.6413 & 0.0236 \\
\hline & & 0.05 & 3.1157636 & -0.9173068 & 2.3154692 & 0.1649904 & 0.7895 & 0.0102 \\
\hline & & 0.10 & 2.4101268 & -0.9831277 & -0.6050786 & 11.350452 & 0.9431 & 0.0068 \\
\hline & \multirow{3}{*}{$\mathrm{F}_{\mathrm{SEAS}}$} & 0.01 & 3.9375752 & 2.048144 & 4.6598029 & 8.3126654 & 0.9538 & 0.0173 \\
\hline & & 0.05 & 2.7463841 & 0.2255762 & 2.1941347 & 0.123433 & 0.7575 & 0.0078 \\
\hline & & 0.10 & 2.2153354 & -0.2166531 & 1.2369 & -0.5729254 & 0.2210 & 0.0053 \\
\hline & \multirow{3}{*}{$\mathrm{F}_{\mathrm{ALL}}$} & 0.01 & 3.4591416 & 13.786047 & -56.194826 & 183.58524 & 0.9972 & 0.0153 \\
\hline & & 0.05 & 2.5003904 & 10.751192 & -52.53282 & 129.29991 & 0.9987 & 0.0068 \\
\hline & & 0.10 & 2.0644772 & 9.6646754 & -51.480407 & 116.29608 & 0.9990 & 0.0050 \\
\hline \multirow{15}{*}{ CASE 2} & \multirow{3}{*}{$\mathrm{t}_{0}$} & 0.01 & -3.42946 & -9.7579046 & 82.481958 & -310.64282 & 0.9962 & 0.0077 \\
\hline & & 0.05 & -2.8745889 & -10.209661 & 100.4063 & -379.1598 & 0.9981 & 0.0046 \\
\hline & & 0.10 & -2.5895772 & -10.773139 & 112.83004 & -431.11607 & 0.9982 & 0.0042 \\
\hline & \multirow{3}{*}{$t_{S / 2}$} & 0.01 & -2.5648603 & -0.7220796 & -1.6630053 & 5.185504 & 0.9064 & 0.0081 \\
\hline & & 0.05 & -1.9396038 & -0.2543905 & -1.2392589 & 9.0240309 & 0.8037 & 0.0043 \\
\hline & & 0.10 & -1.6157063 & -0.1129541 & -1.0298877 & 7.4431335 & 0.6158 & 0.0034 \\
\hline & \multirow{3}{*}{$\mathrm{F}_{\mathrm{K}}$} & 0.01 & 4.731942 & 0.4340476 & 8.7469067 & 23.626831 & 0.8065 & 0.0241 \\
\hline & & 0.05 & 3.1124684 & -1.0782544 & 5.9701458 & 2.9993925 & 0.6250 & 0.0101 \\
\hline & & 0.10 & 2.4105288 & -1.2820898 & 4.6041636 & -0.4866935 & 0.9252 & 0.0068 \\
\hline & \multirow{3}{*}{$\mathrm{F}_{\mathrm{SEAS}}$} & 0.01 & 3.935979 & 2.1304154 & 13.614065 & -16.254418 & 0.9697 & 0.0180 \\
\hline & & 0.05 & 2.7454947 & 0.3471148 & 4.7715588 & 5.4579053 & 0.9297 & 0.0076 \\
\hline & & 0.10 & 2.215263 & -0.1597885 & 3.8089946 & -1.9892152 & 0.6693 & 0.0052 \\
\hline & \multirow{3}{*}{$\mathrm{F}_{\mathrm{ALL}}$} & 0.01 & 4.4016081 & 20.771288 & -121.55971 & 503.01758 & 0.9980 & 0.0172 \\
\hline & & 0.05 & 3.3400212 & 17.111022 & -131.87092 & 508.37418 & 0.9988 & 0.0085 \\
\hline & & 0.10 & 2.8472804 & 15.794686 & -137.3654 & 528.29785 & 0.9989 & 0.0065 \\
\hline \multirow{15}{*}{ CASE 3} & \multirow{3}{*}{$t_{0}$} & 0.01 & -2.5990665 & -12.047061 & 85.687973 & -313.47376 & 0.9982 & 0.0077 \\
\hline & & 0.05 & -1.983883 & -13.928391 & 115.1281 & -418.81782 & 0.9991 & 0.0053 \\
\hline & & 0.10 & -1.6671559 & -15.262401 & 132.19935 & -478.62541 & 0.9993 & 0.0049 \\
\hline & \multirow{3}{*}{$t_{s / 2}$} & 0.01 & -2.5974222 & -12.235628 & 89.523079 & -333.16689 & 0.9980 & 0.0082 \\
\hline & & 0.05 & -1.9841934 & -13.936898 & 115.37681 & -419.67485 & 0.9991 & 0.0053 \\
\hline & & 0.10 & -1.6677888 & -15.228615 & 131.54416 & -474.6252 & 0.9993 & 0.0050 \\
\hline & \multirow{3}{*}{$\mathrm{F}_{\mathrm{K}}$} & 0.01 & 4.7198851 & 26.092445 & -76.364389 & 193.84426 & 0.9982 & 0.0254 \\
\hline & & 0.05 & 3.0977204 & 22.073034 & -68.871248 & 99.894313 & 0.9994 & 0.0112 \\
\hline & & 0.10 & 2.3932811 & 20.125496 & -59.807989 & 47.881951 & 0.9997 & 0.0079 \\
\hline & \multirow{3}{*}{$\mathrm{F}_{\mathrm{SEAS}}$} & 0.01 & 3.8908411 & 32.625569 & -95.725256 & 261.93441 & 0.9993 & 0.0195 \\
\hline & & 0.05 & 2.7031125 & 27.81624 & -96.678618 & 197.87319 & 0.9998 & 0.0090 \\
\hline & & 0.10 & 2.1750663 & 25.43119 & -90.365416 & 151.3075 & 0.9998 & 0.0066 \\
\hline & \multirow{3}{*}{$\mathrm{F}_{\mathrm{ALL}}$} & 0.01 & 3.4294484 & 34.78914 & -100.53054 & 300.41199 & 0.9996 & 0.0166 \\
\hline & & 0.05 & 2.4707113 & 29.916552 & -103.762 & 231.20254 & 0.9998 & 0.0078 \\
\hline & & 0.10 & 2.0364976 & 27.593827 & -100.52671 & 190.05771 & 0.9999 & 0.0060 \\
\hline
\end{tabular}

(Continued) 
Table 3. (Continued)

\begin{tabular}{|c|c|c|c|c|c|c|c|c|}
\hline Deter & Type & $\begin{array}{l}\text { Nominal } \\
\text { size }\end{array}$ & $\theta_{\infty}^{p}$ & $\theta_{1}^{p}$ & $\theta_{2}^{p}$ & $\theta_{3}^{p}$ & $\mathrm{R}^{2}$ & $\hat{\sigma}_{\varepsilon}$ \\
\hline \multirow{15}{*}{ CASE 4} & \multirow{3}{*}{$t_{0}$} & 0.01 & -3.4240594 & -10.555798 & 66.839623 & -252.60934 & 0.9981 & 0.0078 \\
\hline & & 0.05 & -2.8694267 & -10.939314 & 87.891982 & -332.34765 & 0.9991 & 0.0044 \\
\hline & & 0.10 & -2.5859015 & -11.344668 & 99.533099 & -378.36706 & 0.9992 & 0.0039 \\
\hline & \multirow{3}{*}{$t_{s / 2}$} & 0.01 & -2.6002007 & -12.738076 & 87.668208 & -326.35103 & 0.9984 & 0.0081 \\
\hline & & 0.05 & -1.9843278 & -14.491218 & 117.00689 & -429.04365 & 0.9993 & 0.0052 \\
\hline & & 0.10 & -1.6677164 & -15.740811 & 133.48634 & -483.72754 & 0.9993 & 0.0050 \\
\hline & \multirow{3}{*}{$\mathrm{F}_{\mathrm{K}}$} & 0.01 & 4.7204106 & 26.102737 & -70.902319 & 196.40945 & 0.9983 & 0.0255 \\
\hline & & 0.05 & 3.0925571 & 22.430856 & -70.177911 & 106.56658 & 0.9995 & 0.0109 \\
\hline & & 0.10 & 2.387891 & 20.555888 & -63.13051 & 60.869493 & 0.9997 & 0.0076 \\
\hline & \multirow{3}{*}{$\mathrm{F}_{\mathrm{SEAS}}$} & 0.01 & 3.8906697 & 33.381043 & -90.309043 & 273.66357 & 0.9994 & 0.0199 \\
\hline & & 0.05 & 2.7004043 & 28.52364 & -94.29993 & 194.36907 & 0.9998 & 0.0091 \\
\hline & & 0.10 & 2.1718384 & 26.098291 & -89.188768 & 145.03976 & 0.9998 & 0.0068 \\
\hline & \multirow{3}{*}{$\mathrm{F}_{\mathrm{ALL}}$} & 0.01 & 4.3652945 & 41.380478 & -148.50333 & 602.59639 & 0.9996 & 0.0189 \\
\hline & & 0.05 & 3.3081417 & 35.649826 & -161.41505 & 543.9192 & 0.9999 & 0.0087 \\
\hline & & 0.10 & 2.8154926 & 33.24967 & -166.76296 & 535.00317 & 0.9999 & 0.0063 \\
\hline \multirow{15}{*}{ CASE 5} & \multirow{3}{*}{$t_{0}$} & 0.01 & -3.4217626 & -13.179493 & 71.56037 & -301.72588 & 0.9991 & 0.0079 \\
\hline & & 0.05 & -2.8684513 & -13.120393 & 91.33276 & -366.27019 & 0.9995 & 0.0047 \\
\hline & & 0.10 & -2.5849263 & -13.352406 & 103.2619 & -410.92894 & 0.9996 & 0.0041 \\
\hline & \multirow{3}{*}{$t_{S / 2}$} & 0.01 & -3.4250965 & -13.019092 & 69.285867 & \begin{tabular}{|c|}
-291.10874 \\
\end{tabular} & 0.9991 & 0.0076 \\
\hline & & 0.05 & -2.8703909 & -13.034822 & 90.663643 & -366.62196 & 0.9995 & 0.0046 \\
\hline & & 0.10 & -2.5865534 & -13.274299 & 102.48787 & -409.96937 & 0.9996 & 0.0040 \\
\hline & \multirow{3}{*}{$\mathrm{F}_{\mathrm{K}}$} & 0.01 & 8.658319 & 54.666891 & -108.73738 & 537.09139 & 0.9994 & 0.0351 \\
\hline & & 0.05 & 6.5914446 & 47.231376 & -173.72113 & 638.06151 & 0.9998 & 0.0161 \\
\hline & & 0.10 & 5.6307484 & 44.497686 & -199.79752 & 691.47889 & 0.9998 & 0.0115 \\
\hline & \multirow{3}{*}{$\mathrm{F}_{\mathrm{SEAS}}$} & 0.01 & 7.518367 & 64.231225 & -183.85832 & 1080.1022 & 0.9997 & 0.0285 \\
\hline & & 0.05 & 5.955003 & 56.09077 & -246.30303 & 1090.4206 & 0.9999 & 0.0143 \\
\hline & & 0.10 & 5.2153158 & 52.660717 & -268.92965 & 1100.1364 & 0.9999 & 0.0113 \\
\hline & \multirow{3}{*}{$\mathrm{F}_{\mathrm{ALL}}$} & 0.01 & 6.8682745 & 67.762763 & -215.1383 & 1312.4729 & 0.9998 & 0.0252 \\
\hline & & 0.05 & 5.5787523 & 59.621558 & -273.76368 & 1277.0575 & 0.9999 & 0.0140 \\
\hline & & 0.10 & 4.9624761 & 56.003649 & -294.43467 & 1265.369 & 0.9999 & 0.0115 \\
\hline
\end{tabular}

Note: CASE 1 to 5 refers to deterministic terms, which are described in the methodological part. 
Table 4. Quantile coefficients for monthly data, $p=1 \%, 5 \%$ and $10 \%$, OLS detrending

\begin{tabular}{|c|c|c|c|c|c|c|c|c|}
\hline Deter & Type & $\begin{array}{l}\text { Nominal } \\
\text { size }\end{array}$ & $\theta_{\infty}^{p}$ & $\theta_{1}^{p}$ & $\theta_{2}^{p}$ & $\theta_{3}^{p}$ & $R^{2}$ & $\hat{\sigma}_{\varepsilon}$ \\
\hline \multirow{15}{*}{ None } & \multirow{3}{*}{$t_{0}$} & 0.01 & -2.5675401 & 1.3094475 & -2.3015686 & 9.8562761 & 0.9554 & 0.0075 \\
\hline & & 0.05 & -1.9417622 & 1.0719636 & -0.5122449 & 0.5805563 & 0.9822 & 0.0041 \\
\hline & & 0.10 & -1.6175985 & 0.9626317 & -1.0662905 & 5.0677654 & 0.9846 & 0.0033 \\
\hline & \multirow{3}{*}{$t_{s / 2}$} & 0.01 & -2.5664128 & 1.2292061 & -1.2555395 & 6.2523839 & 0.9513 & 0.0078 \\
\hline & & 0.05 & -1.9407732 & 0.9938746 & 0.3436014 & -1.5542122 & 0.9807 & 0.0042 \\
\hline & & 0.10 & -1.6170914 & 0.9163365 & -0.5437617 & 4.0409648 & 0.9842 & 0.0034 \\
\hline & \multirow{3}{*}{$F_{K}$} & 0.01 & 4.7322746 & -2.5629962 & -1.1271589 & 13.311456 & 0.9209 & 0.0221 \\
\hline & & 0.05 & 3.1095037 & -2.0146195 & -1.7868307 & 12.504621 & 0.9764 & 0.0096 \\
\hline & & 0.10 & 2.407046 & -1.6520329 & -2.0280066 & 12.957738 & 0.9842 & 0.0065 \\
\hline & \multirow{3}{*}{$\mathrm{F}_{\text {SEAS }}$} & 0.01 & 2.345647 & 0.2849185 & -1.0546447 & 7.188119 & 0.5709 & 0.0063 \\
\hline & & 0.05 & 1.8775094 & -0.1383075 & -1.2240437 & 5.5672143 & 0.8075 & 0.0031 \\
\hline & & 0.10 & 1.6550286 & -0.2935594 & -1.0243531 & 4.1683709 & 0.9553 & 0.0023 \\
\hline & \multirow{3}{*}{$\mathrm{F}_{\mathrm{ALL}}$} & 0.01 & 2.2890432 & 0.4002036 & -0.6281681 & 5.9506023 & 0.7910 & 0.0060 \\
\hline & & 0.05 & 1.8481484 & -0.0809114 & -0.2333239 & 0.6058961 & 0.5071 & 0.0029 \\
\hline & & 0.10 & 1.6369129 & -0.2188253 & -0.7216096 & 2.8142843 & 0.9287 & 0.0022 \\
\hline \multirow{15}{*}{ CASE 1} & \multirow{3}{*}{$t_{0}$} & 0.01 & -3.4307657 & 1.2029985 & -2.1075018 & 4.2503217 & 0.9507 & 0.0069 \\
\hline & & 0.05 & -2.8610683 & 1.1901521 & -0.8464146 & 1.6992724 & 0.9873 & 0.0038 \\
\hline & & 0.10 & -2.567425 & 1.2274372 & -1.8215069 & 7.6229947 & 0.9918 & 0.0030 \\
\hline & \multirow{3}{*}{$t_{s / 2}$} & 0.01 & -2.5658514 & 1.1654154 & 0.7221767 & -3.4849549 & 0.9534 & 0.0079 \\
\hline & & 0.05 & -1.9400205 & 0.9659154 & 1.2559339 & -5.975413 & 0.9815 & 0.0042 \\
\hline & & 0.10 & -1.6158989 & 0.8510861 & 0.946713 & -3.8560344 & 0.9846 & 0.0034 \\
\hline & \multirow{3}{*}{$\mathrm{F}_{\mathrm{K}}$} & 0.01 & 4.7347231 & -3.1429516 & 3.0630371 & -6.3132977 & 0.9329 & 0.0229 \\
\hline & & 0.05 & 3.1113755 & -2.4513097 & 1.5869998 & -2.506456 & 0.9782 & 0.0102 \\
\hline & & 0.10 & 2.4088408 & -2.025763 & 1.2244484 & -1.9689176 & 0.9850 & 0.0070 \\
\hline & \multirow{3}{*}{$\mathrm{F}_{\mathrm{SEAS}}$} & 0.01 & 2.3447725 & 0.0251582 & 0.9828024 & -3.6657225 & 0.1652 & 0.0062 \\
\hline & & 0.05 & 1.8780538 & -0.3471399 & -0.2138461 & 1.8730848 & 0.9181 & 0.0031 \\
\hline & & 0.10 & 1.6550581 & -0.4510989 & -0.610946 & 3.5495146 & 0.9742 & 0.0023 \\
\hline & \multirow{3}{*}{$\mathrm{F}_{\mathrm{ALL}}$} & 0.01 & 2.5342473 & 0.5701665 & -0.9048796 & 10.131331 & 0.8738 & 0.0065 \\
\hline & & 0.05 & 2.0695665 & -0.0199388 & -0.6262699 & 3.7168939 & 0.1746 & 0.0031 \\
\hline & & 0.10 & 1.8454335 & -0.2328933 & -0.4231408 & 1.5754821 & 0.9167 & 0.0023 \\
\hline \multirow{15}{*}{ CASE 2} & \multirow{3}{*}{$\mathrm{t}_{0}$} & 0.01 & -3.9549846 & 1.0122235 & 3.4984414 & -30.675131 & 0.9563 & 0.0068 \\
\hline & & 0.05 & -3.4083525 & 1.2863159 & 0.5118806 & -6.9046369 & 0.9904 & 0.0037 \\
\hline & & 0.10 & -3.125559 & 1.3222249 & 0.3796422 & -4.9865777 & 0.9943 & 0.0029 \\
\hline & \multirow{3}{*}{$t_{s / 2}$} & 0.01 & -2.566256 & 1.1300491 & 0.4033942 & -3.0012104 & 0.9506 & 0.0077 \\
\hline & & 0.05 & -1.9411086 & 0.9804559 & -0.1545628 & 2.9056916 & 0.9802 & 0.0042 \\
\hline & & 0.10 & -1.6165843 & 0.8409908 & 0.0914484 & 1.7285454 & 0.9838 & 0.0033 \\
\hline & \multirow{3}{*}{$\mathrm{F}_{\mathrm{K}}$} & 0.01 & 4.731919 & -3.4930734 & 1.4612942 & 13.170863 & 0.9211 & 0.0277 \\
\hline & & 0.05 & 3.1100357 & -2.6862001 & 0.7078775 & 7.710322 & 0.9680 & 0.0136 \\
\hline & & 0.10 & 2.4080743 & -2.2397875 & 1.1979622 & 1.7845587 & 0.9766 & 0.0096 \\
\hline & \multirow{3}{*}{$\mathrm{F}_{\text {SEAS }}$} & 0.01 & 2.3445369 & -0.1178548 & -0.6309749 & 10.633739 & 0.1253 & 0.0064 \\
\hline & & 0.05 & 1.8777836 & -0.5155937 & -0.0678793 & 3.9232476 & 0.9546 & 0.0031 \\
\hline & & 0.10 & 1.6550991 & -0.6149477 & -0.3324111 & 5.1974024 & 0.9837 & 0.0023 \\
\hline & \multirow{3}{*}{$\mathrm{F}_{\mathrm{ALL}}$} & 0.01 & 2.7887716 & 0.9817603 & -5.6804247 & 39.999899 & 0.9258 & 0.0066 \\
\hline & & 0.05 & 2.3078427 & 0.0578631 & -1.382916 & 11.691416 & 0.1020 & 0.0032 \\
\hline & & 0.10 & 2.073475 & -0.2250406 & -0.4429236 & 4.0147672 & 0.8833 & 0.0025 \\
\hline
\end{tabular}


Table 4. (Continued)

\begin{tabular}{|c|c|c|c|c|c|c|c|c|}
\hline Deter & Type & $\begin{array}{l}\text { Nominal } \\
\text { size }\end{array}$ & $\theta_{\infty}^{p}$ & $\theta_{1}^{p}$ & $\theta_{2}^{p}$ & $\theta_{3}^{p}$ & $R^{2}$ & $\hat{\sigma}_{\varepsilon}$ \\
\hline \multirow{15}{*}{ CASE 3} & \multirow{3}{*}{$t_{0}$} & 0.01 & -3.4305843 & 2.3483579 & -3.6773595 & 5.3848125 & 0.9861 & 0.0071 \\
\hline & & 0.05 & -2.8622944 & 2.2297365 & -2.8249245 & 8.4082381 & 0.9963 & 0.0036 \\
\hline & & 0.10 & -2.5677525 & 2.0958616 & -2.4516818 & 10.745195 & 0.9976 & 0.0029 \\
\hline & \multirow{3}{*}{$t_{S / 2}$} & 0.01 & -3.4305505 & 2.3500403 & -3.6558281 & 4.4179047 & 0.9856 & 0.0072 \\
\hline & & 0.05 & -2.8606026 & 2.0657875 & 0.1588679 & -6.045421 & 0.9959 & 0.0038 \\
\hline & & 0.10 & -2.5655316 & 1.9159787 & 0.8751589 & -6.1630405 & 0.9973 & 0.0030 \\
\hline & \multirow{3}{*}{$F_{K}$} & 0.01 & 8.8059579 & -10.372729 & 13.962657 & -0.0263542 & 0.9888 & 0.0280 \\
\hline & & 0.05 & 6.6439349 & -8.9382092 & 7.0052185 & 0.8799325 & 0.9971 & 0.0131 \\
\hline & & 0.10 & 5.6291142 & -8.0390517 & 5.5872678 & -5.0031789 & 0.9980 & 0.0098 \\
\hline & \multirow{3}{*}{$\mathrm{F}_{\mathrm{SEAS}}$} & 0.01 & 5.1879385 & 1.8400227 & 0.8305577 & 28.431909 & 0.9761 & 0.0104 \\
\hline & & 0.05 & 4.4703393 & 0.1298514 & -1.454135 & 15.043602 & 0.3688 & 0.0052 \\
\hline & & 0.10 & 4.1108956 & -0.554905 & -2.3373856 & 11.801312 & 0.9615 & 0.0041 \\
\hline & \multirow{3}{*}{$\mathrm{F}_{\mathrm{ALL}}$} & 0.01 & 5.0832624 & 2.4113652 & 2.7749309 & 15.9166 & 0.9866 & 0.0100 \\
\hline & & 0.05 & 4.40506 & 0.5778606 & -0.4386137 & 8.9351938 & 0.9332 & 0.0050 \\
\hline & & 0.10 & 4.0639292 & -0.1534111 & -1.9719314 & 10.047546 & 0.8035 & 0.0038 \\
\hline \multirow{15}{*}{ CASE 4} & \multirow{3}{*}{$\mathrm{t}_{0}$} & 0.01 & -3.9559888 & 2.3216257 & -2.0198937 & -4.5424273 & 0.9876 & 0.0068 \\
\hline & & 0.05 & -3.4088741 & 2.3214439 & -0.852058 & 0.8878269 & 0.9969 & 0.0037 \\
\hline & & 0.10 & -3.125523 & 2.2260245 & 0.3617691 & -1.8467394 & 0.9981 & 0.0029 \\
\hline & \multirow{3}{*}{$t_{S / 2}$} & 0.01 & -3.4282036 & 2.1868232 & -1.0145889 & -6.0207827 & 0.9855 & 0.0072 \\
\hline & & 0.05 & -2.8612384 & 2.1208895 & -0.9676025 & 1.747159 & 0.9957 & 0.0040 \\
\hline & & 0.10 & -2.5661124 & 1.9492966 & 0.1919263 & -1.208689 & 0.9972 & 0.0031 \\
\hline & \multirow{3}{*}{$F_{k}$} & 0.01 & 8.8084506 & -11.014045 & 17.130188 & -7.8454988 & 0.9886 & 0.0294 \\
\hline & & 0.05 & 6.6445821 & -9.2838275 & 7.5795355 & 0.4373092 & 0.9969 & 0.0139 \\
\hline & & 0.10 & 5.6294078 & -8.3078736 & 5.8984249 & -5.4548148 & 0.9980 & 0.0102 \\
\hline & \multirow{3}{*}{$\mathrm{F}_{\mathrm{SEAS}}$} & 0.01 & 5.1872176 & 1.6501231 & 1.3986009 & 22.779383 & 0.9717 & 0.0103 \\
\hline & & 0.05 & 4.4699058 & 0.0051321 & -2.0261104 & 15.795071 & 0.0822 & 0.0052 \\
\hline & & 0.10 & 4.1118809 & -0.771061 & -0.9547951 & 1.6726229 & 0.9751 & 0.0041 \\
\hline & \multirow{3}{*}{$\mathrm{F}_{\mathrm{ALL}}$} & 0.01 & 5.3142769 & 2.698423 & 2.4181515 & 19.104695 & 0.9878 & 0.0104 \\
\hline & & 0.05 & 4.6223044 & 0.7932148 & -2.1911885 & 17.976482 & 0.9464 & 0.0053 \\
\hline & & 0.10 & 4.2759089 & -0.0996844 & -1.6781388 & 5.9888628 & 0.7270 & 0.0040 \\
\hline \multirow{15}{*}{ CASE 5} & \multirow{3}{*}{$\mathrm{t}_{0}$} & 0.01 & -3.9559128 & 2.1481761 & -5.6798976 & 6.2843492 & 0.9781 & 0.0071 \\
\hline & & 0.05 & -3.4087024 & 2.1353073 & -2.8526172 & 10.533851 & 0.9959 & 0.0037 \\
\hline & & 0.10 & -3.1262605 & 2.0826855 & -1.8548174 & 11.965616 & 0.9977 & 0.0029 \\
\hline & \multirow{3}{*}{$t_{s / 2}$} & 0.01 & -3.9600056 & 2.3310207 & -8.2349019 & 17.322549 & 0.9810 & 0.0067 \\
\hline & & 0.05 & -3.4120999 & 2.2749461 & -4.6162299 & 17.309801 & 0.9958 & 0.0038 \\
\hline & & 0.10 & -3.1281091 & 2.1448211 & -2.4136137 & 12.862881 & 0.9976 & 0.0029 \\
\hline & \multirow{3}{*}{$\mathrm{F}_{\mathrm{K}}$} & 0.01 & 12.21408 & -14.953704 & 37.803806 & -35.469902 & 0.9904 & 0.0330 \\
\hline & & 0.05 & 9.7501738 & -13.736069 & 21.923671 & -48.117166 & 0.9979 & 0.0160 \\
\hline & & 0.10 & 8.5753322 & -12.6811 & 14.044172 & -38.983239 & 0.9988 & 0.0118 \\
\hline & \multirow{3}{*}{$\mathrm{F}_{\mathrm{SEAS}}$} & 0.01 & 7.9955643 & 5.5364164 & 9.6733272 & 66.803089 & 0.9964 & 0.0130 \\
\hline & & 0.05 & 7.1481837 & 2.2480373 & 3.1483006 & 14.525138 & 0.9936 & 0.0066 \\
\hline & & 0.10 & 6.7192513 & 0.8071479 & 0.5972514 & -1.3134692 & 0.9643 & 0.0049 \\
\hline & \multirow{3}{*}{$\mathrm{F}_{\mathrm{ALL}}$} & 0.01 & 7.8673893 & 6.576094 & 10.458514 & 64.373974 & 0.9976 & 0.0123 \\
\hline & & 0.05 & 7.0632075 & 3.0625 & 4.7586321 & 7.0607786 & 0.9966 & 0.0063 \\
\hline & & 0.10 & 6.6546712 & 1.5835817 & 0.2754597 & 3.4407029 & 0.9907 & 0.0047 \\
\hline
\end{tabular}

Note: CASE 1 to 5 refers to deterministic terms, which are described in the methodological part; none stands for no deterministic terms. 
Table 5. Quantile coefficients for quarterly data, $p=1 \%, 5 \%$ and $10 \%$, OLS detrending

\begin{tabular}{|c|c|c|c|c|c|c|c|c|}
\hline Deter & Type & $\begin{array}{l}\text { Nominal } \\
\text { size }\end{array}$ & $\theta_{\infty}^{p}$ & $\theta_{1}^{p}$ & $\theta_{2}^{p}$ & $\theta_{3}^{p}$ & $\mathrm{R}^{2}$ & $\hat{\sigma}_{\varepsilon}$ \\
\hline \multirow{15}{*}{ None } & \multirow{3}{*}{$t_{0}$} & 0.01 & -2.5676678 & 0.4751678 & -2.0866101 & 11.057007 & 0.6419 & 0.0081 \\
\hline & & 0.05 & -1.9411654 & 0.6589852 & -1.3763645 & 11.727207 & 0.9512 & 0.0043 \\
\hline & & 0.10 & -1.6168177 & 0.6567624 & -0.679632 & 6.1568001 & 0.9711 & 0.0033 \\
\hline & \multirow{3}{*}{$t_{5 / 2}$} & 0.01 & -2.5677929 & 0.3946104 & -0.5761377 & 3.9353396 & 0.6459 & 0.0082 \\
\hline & & 0.05 & -1.9410209 & 0.5667288 & 1.151301 & -5.4928701 & 0.9501 & 0.0043 \\
\hline & & 0.10 & -1.6167719 & 0.5975269 & 0.6846232 & -1.8546284 & 0.9712 & 0.0033 \\
\hline & \multirow{3}{*}{$\mathrm{F}_{\mathrm{K}}$} & 0.01 & 4.729882 & 1.2719035 & -1.246289 & 15.707069 & 0.7255 & 0.0238 \\
\hline & & 0.05 & 3.1105441 & -0.4746164 & -0.5826716 & 7.0978537 & 0.6564 & 0.0099 \\
\hline & & 0.10 & 2.4094103 & -0.8841471 & 1.7175107 & -9.3520629 & 0.9248 & 0.0067 \\
\hline & \multirow{3}{*}{$\mathrm{F}_{\mathrm{SEAS}}$} & 0.01 & 3.9360076 & 2.1138295 & 1.5101301 & 2.2413873 & 0.9369 & 0.0177 \\
\hline & & 0.05 & 2.7444305 & 0.3096088 & -0.9951215 & 7.6669009 & 0.5392 & 0.0078 \\
\hline & & 0.10 & 2.2154677 & -0.2696407 & 0.6770328 & -2.6692922 & 0.5989 & 0.0055 \\
\hline & \multirow{3}{*}{$\mathrm{F}_{\mathrm{ALL}}$} & 0.01 & 3.4810704 & 2.844462 & -0.7330297 & 23.059449 & 0.9749 & 0.0143 \\
\hline & & 0.05 & 2.5212908 & 0.7868214 & -0.1738385 & 3.630294 & 0.9314 & 0.0065 \\
\hline & & 0.10 & 2.0866174 & 0.1436252 & 0.666834 & -3.181357 & 0.5985 & 0.0044 \\
\hline \multirow{15}{*}{ CASE 1} & \multirow{3}{*}{$t_{0}$} & 0.01 & -3.427993 & -0.5812201 & 2.5521031 & -28.067062 & 0.8580 & 0.0073 \\
\hline & & 0.05 & -2.8602236 & 0.2317073 & 1.0513884 & -9.7978441 & 0.7477 & 0.0042 \\
\hline & & 0.10 & -2.5660487 & 0.4984623 & 0.5006179 & -4.2384347 & 0.9572 & 0.0032 \\
\hline & \multirow{3}{*}{$t_{S / 2}$} & 0.01 & -2.5654843 & 0.3327896 & 2.0609683 & -11.813474 & 0.7229 & 0.0079 \\
\hline & & 0.05 & -1.9409957 & 0.6440714 & 0.1991937 & 1.7642012 & 0.9562 & 0.0043 \\
\hline & & 0.10 & -1.6169878 & 0.6647643 & -0.0583101 & 3.1426989 & 0.9737 & 0.0034 \\
\hline & \multirow{3}{*}{$\mathrm{F}_{\mathrm{k}}$} & 0.01 & 4.7324106 & -0.1066813 & 1.2958689 & 28.570727 & 0.1815 & 0.0235 \\
\hline & & 0.05 & 3.1101654 & -1.3008103 & -0.0784826 & 18.377518 & 0.9177 & 0.0099 \\
\hline & & 0.10 & 2.4091106 & -1.4663395 & 0.2107927 & 13.804404 & 0.9706 & 0.0067 \\
\hline & \multirow{3}{*}{$\mathrm{F}_{\mathrm{SEAS}}$} & 0.01 & 3.9340198 & 1.3414927 & -1.2242778 & 37.889254 & 0.8836 & 0.0174 \\
\hline & & 0.05 & 2.7441775 & -0.3138404 & -0.85485 & 16.809288 & 0.4560 & 0.0077 \\
\hline & & 0.10 & 2.2145428 & -0.6840994 & -0.8512198 & 13.143561 & 0.9292 & 0.0052 \\
\hline & \multirow{3}{*}{$\mathrm{F}_{\mathrm{ALL}}$} & 0.01 & 4.3786638 & 4.8517259 & -6.4152528 & 81.284739 & 0.9883 & 0.0162 \\
\hline & & 0.05 & 3.3069139 & 1.6576716 & -3.9239019 & 37.87116 & 0.9777 & 0.0073 \\
\hline & & 0.10 & 2.8079755 & 0.6079089 & -1.7231322 & 15.977384 & 0.9177 & 0.0052 \\
\hline \multirow{15}{*}{ CASE 2} & \multirow{3}{*}{$\mathrm{t}_{0}$} & 0.01 & -3.9578302 & -0.9506303 & 0.0452801 & -18.612543 & 0.9534 & 0.0075 \\
\hline & & 0.05 & -3.4096333 & 0.0572423 & 0.6236054 & -9.3269809 & 0.0788 & 0.0039 \\
\hline & & 0.10 & -3.1271451 & 0.4822495 & -0.5244749 & 0.7931118 & 0.9475 & 0.0030 \\
\hline & \multirow{3}{*}{$t_{S / 2}$} & 0.01 & -2.5667639 & 0.1769365 & 0.6995052 & -5.30954 & 0.3393 & 0.0081 \\
\hline & & 0.05 & -1.9411076 & 0.4432638 & 0.8543688 & -3.217485 & 0.9196 & 0.0044 \\
\hline & & 0.10 & -1.6167623 & 0.4695933 & 0.6407396 & -1.1257551 & 0.9534 & 0.0035 \\
\hline & \multirow{3}{*}{$\mathrm{F}_{\mathrm{K}}$} & 0.01 & 4.731581 & -1.5950089 & 6.5630488 & 32.858942 & 0.3827 & 0.0240 \\
\hline & & 0.05 & 3.1104266 & -2.4251299 & 6.5757176 & -2.626365 & 0.9670 & 0.0096 \\
\hline & & 0.10 & 2.4090477 & -2.3224461 & 5.2016427 & -3.3865231 & 0.9859 & 0.0064 \\
\hline & \multirow{3}{*}{$\mathrm{F}_{\mathrm{SEAS}}$} & 0.01 & 3.9358326 & 0.4744963 & 0.5497029 & 59.866301 & 0.8154 & 0.0169 \\
\hline & & 0.05 & 2.745062 & -1.0033942 & 3.0899005 & 9.5584463 & 0.8420 & 0.0075 \\
\hline & & 0.10 & 2.2156122 & -1.2923094 & 3.4962851 & -1.1475224 & 0.9666 & 0.0051 \\
\hline & \multirow{3}{*}{$\mathrm{F}_{\mathrm{ALL}}$} & 0.01 & 5.2504668 & 6.3605264 & 0.5489734 & 83.53286 & 0.9927 & 0.0186 \\
\hline & & 0.05 & 4.093603 & 2.4357024 & -1.195847 & 36.041727 & 0.9892 & 0.0083 \\
\hline & & 0.10 & 3.5482854 & 1.0664806 & -0.6092601 & 17.885635 & 0.9723 & 0.0060 \\
\hline
\end{tabular}


Table 5. (Continued)

\begin{tabular}{|c|c|c|c|c|c|c|c|c|}
\hline Deter & Type & $\begin{array}{l}\text { Nominal } \\
\text { size }\end{array}$ & $\theta_{\infty}^{p}$ & $\theta_{1}^{p}$ & $\theta_{2}^{p}$ & $\theta_{3}^{p}$ & $R^{2}$ & $\hat{\sigma}_{\varepsilon}$ \\
\hline \multirow{15}{*}{ CASE 3} & \multirow{3}{*}{$t_{0}$} & 0.01 & -3.4297763 & 0.3600138 & 0.0481116 & -26.143721 & 0.2619 & 0.0076 \\
\hline & & 0.05 & -2.860673 & 0.9722348 & 0.2604524 & -9.29901 & 0.9774 & 0.0041 \\
\hline & & 0.10 & -2.5665713 & 1.1718978 & -0.1708337 & -1.9030244 & 0.9911 & 0.0032 \\
\hline & \multirow{3}{*}{$t_{s / 2}$} & 0.01 & -3.4286971 & 0.3977295 & -1.8735404 & -12.559216 & 0.2061 & 0.0074 \\
\hline & & 0.05 & -2.8616439 & 1.0286748 & -0.8145006 & -3.3678362 & 0.9792 & 0.0039 \\
\hline & & 0.10 & -2.5669902 & 1.177482 & -0.1806585 & -2.3249076 & 0.9913 & 0.0031 \\
\hline & \multirow{3}{*}{$\mathrm{F}_{\mathrm{K}}$} & 0.01 & 8.8019274 & 3.3538848 & 14.277935 & 70.72439 & 0.9656 & 0.0318 \\
\hline & & 0.05 & 6.6424614 & -0.926679 & 2.4713914 & 34.417913 & 0.3673 & 0.0147 \\
\hline & & 0.10 & 5.6266552 & -2.138732 & -0.0650036 & 22.338578 & 0.9650 & 0.0108 \\
\hline & \multirow{3}{*}{$\mathrm{F}_{\mathrm{SEAS}}$} & 0.01 & 7.5396048 & 7.5991821 & 8.7130426 & 104.98413 & 0.9924 & 0.0250 \\
\hline & & 0.05 & 5.9104902 & 1.9392848 & 5.3296319 & 18.793816 & 0.9796 & 0.0117 \\
\hline & & 0.10 & 5.1271615 & 0.3200734 & -0.9572912 & 25.507557 & 0.7386 & 0.0087 \\
\hline & \multirow{3}{*}{$\mathrm{F}_{\mathrm{ALL}}$} & 0.01 & 6.8331686 & 10.088421 & 11.745679 & 108.79019 & 0.9962 & 0.0228 \\
\hline & & 0.05 & 5.4859552 & 4.2840335 & 1.1083491 & 45.083524 & 0.9949 & 0.0104 \\
\hline & & 0.10 & 4.835543 & 2.0705299 & -0.8664969 & 26.985332 & 0.9872 & 0.0077 \\
\hline \multirow{15}{*}{ CASE 4} & \multirow{3}{*}{$t_{0}$} & 0.01 & -3.9591996 & 0.0092665 & -3.2784932 & -20.098089 & 0.8393 & 0.0076 \\
\hline & & 0.05 & -3.4091581 & 0.7622415 & 0.7557244 & -14.45085 & 0.9643 & 0.0040 \\
\hline & & 0.10 & -3.1264299 & 1.1007609 & 0.4040567 & -3.7484708 & 0.9916 & 0.0030 \\
\hline & \multirow{3}{*}{$t_{s / 2}$} & 0.01 & -3.4288406 & 0.4397071 & -2.9928732 & -7.7696786 & 0.1881 & 0.0076 \\
\hline & & 0.05 & -2.8613813 & 1.0097287 & -0.8642377 & -1.1243402 & 0.9784 & 0.0040 \\
\hline & & 0.10 & -2.5670798 & 1.1690247 & -0.4872639 & 1.8289946 & 0.9917 & 0.0031 \\
\hline & \multirow{3}{*}{$\mathrm{F}_{\mathrm{K}}$} & 0.01 & 8.8079433 & 1.3768422 & 27.927537 & 43.673534 & 0.9563 & 0.0313 \\
\hline & & 0.05 & 6.6484906 & -2.4078609 & 13.518526 & -6.3163026 & 0.8210 & 0.0149 \\
\hline & & 0.10 & 5.6313541 & -3.1794977 & 5.3193418 & 5.0928481 & 0.9812 & 0.0105 \\
\hline & \multirow{3}{*}{$\mathrm{F}_{\mathrm{SEAS}}$} & 0.01 & 7.54305 & 6.4424174 & 17.852255 & 94.686737 & 0.9913 & 0.0261 \\
\hline & & 0.05 & 5.9137395 & 1.1626669 & 11.496638 & -3.2857448 & 0.9724 & 0.0119 \\
\hline & & 0.10 & 5.1309255 & -0.3861874 & 4.8934131 & 2.3557045 & 0.3586 & 0.0088 \\
\hline & \multirow{3}{*}{$\mathrm{F}_{\mathrm{ALL}}$} & 0.01 & 7.6191556 & 12.07151 & 16.260612 & 157.81323 & 0.9974 & 0.0237 \\
\hline & & 0.05 & 6.2116903 & 5.0771543 & 9.0521913 & 24.511814 & 0.9966 & 0.0110 \\
\hline & & 0.10 & 5.5243556 & 2.7015249 & 1.4485982 & 23.006445 & 0.9928 & 0.0079 \\
\hline \multirow{15}{*}{ CASE 5} & \multirow{3}{*}{$t_{0}$} & 0.01 & -3.9588101 & -0.2609943 & -6.8041457 & -28.5541 & 0.9646 & 0.0076 \\
\hline & & 0.05 & -3.4103017 & 0.607464 & -2.5274287 & -11.745063 & 0.7679 & 0.0040 \\
\hline & & 0.10 & -3.1270704 & 0.9216108 & -1.8381578 & 0.6206047 & 0.9802 & 0.0031 \\
\hline & \multirow{3}{*}{$t_{s / 2}$} & 0.01 & -3.9592924 & -0.2064835 & -6.981935 & -31.230843 & 0.9638 & 0.0076 \\
\hline & & 0.05 & -3.410415 & 0.5905968 & -2.1206633 & -13.207976 & 0.7949 & 0.0038 \\
\hline & & 0.10 & -3.1275135 & 0.9040293 & -1.2230855 & -2.8750693 & 0.9818 & 0.0030 \\
\hline & \multirow{3}{*}{$\mathrm{F}_{\mathrm{K}}$} & 0.01 & 12.207936 & 9.5227497 & 22.455666 & 358.7622 & 0.9925 & 0.0408 \\
\hline & & 0.05 & 9.7445908 & 1.5427798 & 9.9435242 & 98.777146 & 0.9742 & 0.0180 \\
\hline & & 0.10 & 8.5712092 & -0.9858562 & 2.469288 & 52.913858 & 0.3884 & 0.0133 \\
\hline & \multirow{3}{*}{$\mathrm{F}_{\text {SEAS }}$} & 0.01 & 10.750947 & 16.028405 & 21.898973 & 446.20257 & 0.9977 & 0.0330 \\
\hline & & 0.05 & 8.8662471 & 6.7413723 & 10.22886 & 135.52841 & 0.9972 & 0.0146 \\
\hline & & 0.10 & 7.9494832 & 3.3764254 & 3.6260652 & 67.391514 & 0.9934 & 0.0109 \\
\hline & \multirow{3}{*}{$\mathrm{F}_{\mathrm{ALL}}$} & 0.01 & 9.9188917 & 20.406505 & 17.886062 & 501.64223 & 0.9988 & 0.0280 \\
\hline & & 0.05 & 8.3530514 & 10.128553 & 9.8759863 & 159.10682 & 0.9989 & 0.0129 \\
\hline & & 0.10 & 7.5807963 & 6.4076414 & -0.0392215 & 101.85158 & 0.9981 & 0.0098 \\
\hline
\end{tabular}

Note: CASE 1 to 5 refers to deterministic terms, which are described in the methodological part; none stands for no deterministic terms. 
Table 6. Critical values obtained from the response surface with low $R^{2}$ compared to the table values

\begin{tabular}{|c|c|c|c|c|c|c|c|c|}
\hline \multicolumn{9}{|c|}{ Smith and Taylor (1998), quarterly frequency } \\
\hline \multirow[b]{2}{*}{ Sample } & \multicolumn{2}{|c|}{ CASE $5, F_{K}, 10 \%$} & & & & & & \\
\hline & Table & Surface & & & & & & \\
\hline 12 & 8.59 & 8.537 & & & & & & \\
\hline 25 & 8.49 & 8.539 & & & & & & \\
\hline 34 & 8.51 & 8.546 & & & & & & \\
\hline 50 & 8.51 & 8.553 & & & & & & \\
\hline 100 & 8.51 & 8.562 & & & & & & \\
\hline $\mathrm{R}^{2}$ & & 0.388 & & & & & & \\
\hline \multicolumn{9}{|c|}{ Franses and Hobijn (1997), quarterly frequency } \\
\hline & \multicolumn{2}{|c|}{ CASE $2, \mathrm{t}_{0}, 5 \%$} & \multicolumn{2}{|c|}{ CASE $1, \mathrm{~F}_{\mathrm{K}}, 1 \%$} & \multicolumn{2}{|c|}{ CASE $4, t_{s / 2}, 1 \%$} & \multicolumn{2}{|c|}{ CASE $2, t_{S / 2}, 1 \%$} \\
\hline Sample & Table & Surface & Table & Surface & Table & Surface & Table & Surface \\
\hline 10 & -3.34 & -3.407 & 4.95 & 4.763 & -3.40 & -3.423 & -2.49 & -2.547 \\
\hline 20 & -3.38 & -3.406 & 4.83 & 4.734 & -3.41 & -3.415 & -2.52 & -2.557 \\
\hline 30 & -3.41 & -3.407 & 4.61 & 4.731 & -3.40 & -3.418 & -2.52 & -2.560 \\
\hline 40 & -3.40 & -3.408 & 4.83 & 4.731 & -3.41 & -3.420 & -2.53 & -2.562 \\
\hline $\mathrm{R}^{2}$ & & 0.079 & & 0.182 & & 0.188 & & 0.339 \\
\hline \multicolumn{9}{|c|}{ Franses and Hobijn (1997), monthly frequency } \\
\hline & \multicolumn{2}{|c|}{ CASE $4, \mathrm{~F}_{\mathrm{SEAS}}, 5 \%$} & \multicolumn{2}{|c|}{ CASE $2, \mathrm{~F}_{\mathrm{ALL}}, 5 \%$} & \multicolumn{2}{|c|}{ CASE $2, \mathrm{~F}_{\mathrm{SEAS}}, 1 \%$} & \multicolumn{2}{|c|}{ CASE $1, \mathrm{~F}_{\mathrm{SEAS}}, 1 \%$} \\
\hline Sample & Table & Surface & Table & Surface & Table & Surface & Table & Surface \\
\hline 10 & 4.50 & 4.466 & 2.35 & 2.311 & 2.38 & 2.337 & 2.40 & 2.353 \\
\hline 20 & 4.46 & 4.467 & 2.32 & 2.309 & 2.35 & 2.338 & 2.38 & 2.348 \\
\hline 30 & 4.47 & 4.468 & 2.33 & 2.309 & 2.33 & 2.340 & 2.34 & 2.347 \\
\hline 40 & 4.44 & 4.469 & 2.30 & 2.309 & 2.36 & 2.341 & 2.36 & 2.346 \\
\hline $\mathrm{R}^{2}$ & & 0.082 & & 0.102 & & 0.125 & & 0.165 \\
\hline
\end{tabular}

Note: CASE 1 to 5 refers to deterministic terms, which are described in the methodological part. 
Table 7. Critical values that differ from previous studies

\begin{tabular}{|c|c|c|c|c|c|c|c|}
\hline \multicolumn{8}{|c|}{ HEGY (1990), quarterly frequency } \\
\hline $\begin{array}{l}\text { Sample } \\
\text { size }\end{array}$ & $\begin{array}{c}\text { Type of } \\
\text { statistics }\end{array}$ & $\begin{array}{c}\text { Deterministic } \\
\text { terms }\end{array}$ & $\begin{array}{l}\text { Nominal } \\
\text { size }\end{array}$ & $\begin{array}{c}\text { Published } \\
\text { CV }\end{array}$ & $\begin{array}{c}\text { Calculated } \\
p \text {-value }\end{array}$ & $\begin{array}{c}p \text {-value } \\
\text { difference }\end{array}$ & $\begin{array}{c}\text { Suggested } \\
\text { CV }\end{array}$ \\
\hline 48 & $t_{0}$ & CASE 4 & 0.10 & -3.37 & 0.0476 & 0.0524 & -3.03 \\
\hline 48 & $t_{s / 2}$ & CASE 4 & 0.10 & -2.73 & 0.0567 & 0.0433 & -2.47 \\
\hline 48 & $t_{0}$ & CASE 3 & 0.10 & -2.72 & 0.0579 & 0.0421 & -2.47 \\
\hline 48 & $t_{s / 2}$ & CASE 3 & 0.10 & -2.69 & 0.0620 & 0.0380 & -2.47 \\
\hline 48 & $t_{0}$ & CASE 4 & 0.05 & -3.71 & 0.0209 & 0.0291 & -3.35 \\
\hline 100 & $t_{0}$ & CASE 4 & 0.10 & -3.22 & 0.0732 & 0.0268 & -3.08 \\
\hline 48 & $t_{0}$ & CASE 3 & 0.05 & -3.08 & 0.0242 & 0.0258 & -2.78 \\
\hline 48 & $t_{s / 2}$ & CASE 4 & 0.05 & -3.08 & 0.0243 & 0.0257 & -2.78 \\
\hline 136 & $t_{0}$ & CASE 4 & 0.10 & -3.21 & 0.0767 & 0.0233 & -3.09 \\
\hline 48 & $t_{s / 2}$ & CASE 3 & 0.05 & -3.04 & 0.0268 & 0.0232 & -2.78 \\
\hline 48 & $t_{0}$ & CASE 2 & 0.10 & -3.21 & 0.0776 & 0.0224 & -3.09 \\
\hline 100 & $t_{0}$ & CASE 3 & 0.10 & -2.63 & 0.0785 & 0.0215 & -2.52 \\
\hline 100 & $t_{s / 2}$ & CASE 3 & 0.10 & -2.63 & 0.0785 & 0.0215 & -2.52 \\
\hline 100 & $t_{s / 2}$ & CASE 4 & 0.10 & -2.63 & 0.0786 & 0.0214 & -2.52 \\
\hline \multicolumn{8}{|c|}{ Rodrigues and Taylor (2007), quarterly frequency, GLS case } \\
\hline 48 & $\mathrm{~F}_{\text {CASE } 3}$ & CASE 4 & 0.10 & 3.97 & 0.9140 & -0.0140 & 3.81 \\
\hline 48 & $\mathrm{~F}_{\mathrm{ALL}}$ & CASE 3 & 0.10 & 3.88 & 0.9134 & -0.0134 & 3.75 \\
\hline 48 & $\mathrm{~F}_{\mathrm{ALL}}$ & CASE 4 & 0.10 & 4.89 & 0.9132 & -0.0132 & 4.74 \\
\hline 48 & $\mathrm{~F}_{\text {CASE } 3}$ & CASE 3 & 0.10 & 3.89 & 0.9123 & -0.0123 & 3.75 \\
\hline 48 & $\mathrm{~F}_{\mathrm{K}}$ & CASE 4 & 0.10 & 3.85 & 0.9118 & -0.0118 & 3.70 \\
\hline 48 & $\mathrm{~F}_{\mathrm{ALL}}$ & CASE 5 & 0.10 & 8.50 & 0.9110 & -0.0110 & 8.32 \\
\hline 48 & $\mathrm{~F}_{\mathrm{CASE} 3}$ & CASE 5 & 0.10 & 8.56 & 0.9103 & -0.0103 & 8.37 \\
\hline 48 & $\mathrm{~F}_{\mathrm{K}}$ & CASE 3 & 0.10 & 3.81 & 0.9100 & -0.0100 & 3.68 \\
\hline \multicolumn{8}{|c|}{ Franses and Hobijn (1997), quarterly frequency } \\
\hline 40 & $t_{0}$ & CASE 2 & 0.10 & -3.03 & 0.1113 & -0.0113 & -3.08 \\
\hline 40 & $\mathrm{~F}_{\mathrm{K}}$ & none & 0.10 & 2.44 & 0.9101 & -0.0101 & 2.33 \\
\hline \multicolumn{8}{|c|}{ Franses and Hobijn (1997), monthly frequency } \\
\hline 120 & $\mathrm{~F}_{\mathrm{ALL}}$ & none & 0.10 & 1.65 & 0.9110 & -0.0110 & 1.61 \\
\hline 120 & $\mathrm{~F}_{\text {CASE } 3}$ & none & 0.10 & 1.66 & 0.9109 & -0.0109 & 1.62 \\
\hline 360 & $\mathrm{~F}_{\mathrm{ALL}}$ & CASE 1 & 0.01 & 2.34 & 0.9793 & 0.0107 & 2.55 \\
\hline 120 & $t_{0}$ & CASE 2 & 0.10 & -2.95 & 0.1105 & -0.0105 & 2.99 \\
\hline
\end{tabular}

Note: CASE 1 to 5 refers to deterministic terms, which are described in the methodological part; none stands for no deterministic terms. 
Table 8. Cross verification results

\begin{tabular}{|c|c|c|c|c|c|c|}
\hline $\begin{array}{l}\text { Sample } \\
\text { size }\end{array}$ & $\begin{array}{c}\text { Type of } \\
\text { statistics }\end{array}$ & $\begin{array}{l}\text { Deterministic } \\
\text { terms }\end{array}$ & $\begin{array}{c}\text { CV reported } \\
\text { by Franses } \\
\text { and Hobijn } \\
(1997)\end{array}$ & $\begin{array}{l}\text { Nominal size } \\
\text { reported by } \\
\text { Franses and } \\
\text { Hobijn (1997) }\end{array}$ & $\begin{array}{c}p \text {-value, by } \\
\text { Diaz- } \\
\text { Emparanza } \\
(2014)\end{array}$ & Our $p$-value \\
\hline \multicolumn{7}{|c|}{ Monthly frequency } \\
\hline 480 & $\mathrm{~F}_{\mathrm{SEAS}}$ & CASE 1 & 1.66 & 0.10 & 0.202 & 0.095 \\
\hline 480 & $\mathrm{~F}_{\mathrm{ALL}}$ & CASE1 & 1.84 & 0.10 & 0.169 & 0.100 \\
\hline 480 & $\mathrm{~F}_{\mathrm{SEAS}}$ & CASE2 & 1.66 & 0.10 & 0.201 & 0.094 \\
\hline 480 & $\mathrm{~F}_{\mathrm{ALL}}$ & CASE2 & 2.07 & 0.10 & 0.134 & 0.099 \\
\hline 480 & $\mathrm{~F}_{\mathrm{SEAS}}$ & CASE3 & 4.08 & 0.10 & 0.232 & 0.103 \\
\hline 480 & $\mathrm{~F}_{\mathrm{ALL}}$ & CASE3 & 4.04 & 0.10 & 0.238 & 0.104 \\
\hline 480 & $\mathrm{~F}_{\mathrm{SEAS}}$ & CASE4 & 4.07 & 0.10 & 0.233 & 0.104 \\
\hline 480 & $\mathrm{~F}_{\mathrm{ALL}}$ & CASE4 & 4.26 & 0.10 & 0.207 & 0.102 \\
\hline \multicolumn{7}{|c|}{ Quarterly frequency } \\
\hline 160 & $\mathrm{~F}_{\mathrm{SEAS}}$ & CASE 1 & 2.20 & 0.10 & 0.121 & 0.100 \\
\hline 160 & $\mathrm{~F}_{\mathrm{ALL}}$ & CASE1 & 2.83 & 0.10 & 0.066 & 0.099 \\
\hline 160 & $\mathrm{~F}_{\mathrm{SEAS}}$ & CASE2 & 2.18 & 0.10 & 0.121 & 0.101 \\
\hline 160 & $\mathrm{~F}_{\mathrm{ALL}}$ & CASE2 & 3.59 & 0.10 & 0.031 & 0.098 \\
\hline 160 & $\mathrm{~F}_{\mathrm{SEAS}}$ & CASE3 & 5.09 & 0.10 & 0.122 & 0.104 \\
\hline 160 & $\mathrm{~F}_{\mathrm{ALL}}$ & CASE3 & 4.86 & 0.10 & 0.141 & 0.103 \\
\hline 160 & $\mathrm{~F}_{\mathrm{SEAS}}$ & CASE4 & 5.09 & 0.10 & 0.118 & 0.103 \\
\hline 160 & $\mathrm{~F}_{\mathrm{AL}}$ & CASE4 & 5.55 & 0.10 & 0.087 & 0.104 \\
\hline
\end{tabular}

Note: CASE 1 to 5 refers to deterministic terms, which are described in the methodological part. 